Working Paper/Document de travail 2012-28

\title{
What Drags and Drives Mobility: Explaining Canada's Aggregate Migration Patterns
}

by David Amirault, Daniel de Munnik and Sarah Miller 
Bank of Canada Working Paper 2012-28

August 2012

\title{
What Drags and Drives Mobility: Explaining Canada's Aggregate Migration Patterns
}

\author{
by \\ David Amirault, Daniel de Munnik and Sarah Miller \\ Canadian Economic Analysis Department \\ Bank of Canada \\ Ottawa, Ontario, Canada K1A 0G9 \\ Corresponding author: dmunnik@bankofcanada.ca
}

Bank of Canada working papers are theoretical or empirical works-in-progress on subjects in economics and finance. The views expressed in this paper are those of the authors.

No responsibility for them should be attributed to the Bank of Canada. 


\section{Acknowledgements}

The authors wish to thank participants of the 2012 CEA Conference, Bob Amano, Jean Boivin, Brigid Brady, Bob Fay, Paul Fenton, Sharon Kozicki, Tiff Macklem, John Murray, Lise Pichette, Lori Rennison, and other members of the Regional Analysis Division of the Bank of Canada for their support. We would also like to thank Jason Jacques and Trevor MacKay for their work on this project in the early days, and Tara Ainsworth for her assistance in putting this dataset together. 


\begin{abstract}
Using census data at the economic region level from 1991 to 2006 and a gravity model framework, this paper examines the factors that influence migration within Canada. Results from both Poisson pseudo-maximum likelihood and negative binominal regression models suggest that provincial borders are statistically significant barriers to migration but the magnitude of their effect varies by model specification. The regression results also indicate that differences in employment rates, household incomes and language are important in explaining migration between Canadian economic regions. We also find evidence that the negative effect of distance on migration may be declining over time.

JEL classification: J61, R23

Bank classification: Regional economic developments; Labour markets; Econometric and statistical methods
\end{abstract}

\title{
Résumé
}

Dans un cadre gravitationnel et à l'aide de données ventilées par région tirées du recensement pour les années 1991 à 2006, les auteurs étudient les facteurs qui influent sur la migration interrégionale au Canada. Les résultats qu'ils tirent de l'estimation de modèles de Poisson par la méthode du pseudo-maximum de vraisemblance ainsi que de modèles de régression binomiale négative donnent à penser que les frontières provinciales sont un frein statistiquement significatif à la migration, mais l'ampleur de l'effet varie selon la spécification du modèle. Les résultats indiquent aussi que les disparités en matière de taux d'emploi et de revenu des ménages et les différences de langue sont des facteurs déterminants des flux migratoires entre les régions économiques du Canada. Enfin, les auteurs notent que l'effet dissuasif de la distance diminue peut-être avec le temps.

Classification JEL : J61, R23

Classification de la Banque : Évolution économique régionale; Marchés du travail; Méthodes économétriques et statistiques 


\section{Introduction}

Policy makers' understanding of an economy's ability to adjust to macroeconomic shocks is crucial for setting the appropriate policy response to economic events. The reallocation of labour within an economy is a key element of this adjustment process. In Canada, like other small open commodityproducing economies with a flexible exchange rate, terms of trade shocks can create significant variations in labour market outcomes when the resource and manufacturing sectors are disproportionately distributed across the country (Lefebvre and Poloz 1996).

The recent commodity boom illustrates the role that terms of trade shocks play in the relative performance of Canadian regions and ensuing migration to commodity-producing regions. Alberta's disproportionately large endowment of commodities explains why its labour market pulled from all other provinces (except British Columbia which also benefitted from stronger commodity prices) over the mid-2000s. Chart 1 uses Canadian Census data to show the migration to each economic region by source between 2001 and 2006, the period over which the migration trend to Alberta peaked. It illustrates the extent to which the commodity boom pulled in workers from elsewhere to supply the strong growth in labour demand in specific parts of Alberta. ${ }^{1}$ While the inter-provincial flows (across provinces, green bars) nearly match intra-provincial flows (within provinces, red bars) in the case of Alberta, in terms of total migration in Canada, intra-provincial migration during the same period played a larger role in redistributing potential labour supply.

Table 1 presents the flow of intra-provincial and inter-provincial migrants in each intercensal period, and illustrates several points. First, many Canadians move each intercensal period. On average, during these three periods, 8.4 per cent of the total population moved from one economic region to another. Also, consistent with findings in Chart 1, in each period, the number of intra-provincial migrants is much higher than the number of inter-provincial migrants, almost by a factor of 2 . Mean values of migration between economic regions with and without a provincial border are 204 and 2679, respectively. These two findings provide evidence that provincial borders matter for migration. Finally, the table shows that the number of intra-provincial and inter-provincial migrants each period is roughly the same.

Although this paper estimates the relationship between several variables and aggregate migration, one of its main contributions to the literature is to estimate the effect of provincial borders. Not only is evidence of a border effect on migration of interest in itself but it may also provide insight into trade flows. There are a number of empirical studies that find that borders have negative effects

\footnotetext{
${ }^{1}$ Recent migrants are defined as individuals who moved to the economic region in the past five years based on the previous census.
} 
on trade (Millimet and Osang 2007, Anderson and Van Wincoop 2003, Wall 2000, Helliwell 1997, McCallum 1995). Such results are unexpected given the decline in many barriers to international trade and the lack of barriers to intra-national trade. Millimet and Osang (2007), in an effort to explain this "puzzle" ${ }^{2}$, find that once migration is controlled for, the border effect on trade between U.S. states disappears. They suggest that migrants proxy for unobserved network effects, a key factor that had been overlooked in past work. Given this, the question then becomes, is there a border effect on migration? In the Canadian context ${ }^{3}$, research on aggregate migration has almost exclusively focused on migration at the provincial level (Coulombe 2006, Helliwell 1997, Foot and Milne 1984). As these analyses do not have sub-provincial migration data, they can not estimate the effect of the provincial borders on migration. However, Helliwell's (1997) analysis also includes data on flows from the U.S. to Canada, and finds that the indicator variable identifying such flows is statistically significant and negative. The estimated border effect is roughly 100 , which implies that, all else held constant, for every U.S. born resident now living in a particular Canadian province, there are 100 out-of-province residents. These studies are also limited in the estimation of the influence of other variables on migration since, as pointed out in Table 1, only roughly one third of migration (between economic regions ${ }^{4}$ ) involves movement across provinces, the rest occurs within provincial borders. While a few papers have examined Canadian migration at the sub-provincial level (Flowerdew and Amrhein 1989, Shaw 1986, Simmons 1980), none include a variable to estimate a border effect. Flowerdew and Amrhein (1989) and Simmons (1980) are also limited in explaining migration since their analyses use flows at the census division level, which captures short distance movers whose migration decisions are based on different factors than those of long distance migrants. ${ }^{5}$ Similarly, Shaw (1986) only considers migration between major cities and therefore also ignores the significant variation in rural to urban, and urban to urban, migration flows over time.

This paper uses Canadian census data from 1991-2006, corresponding to three intercensal periods, and a gravity model framework to explain aggregate gross migration flows between economic regions. Not only does our sub-provincial data allow us to contribute to the literature by estimating an

\footnotetext{
${ }^{2}$ In a seminal paper, Obstfeld and Rogoff (2000) argue that the unexpected border effect on trade is one of the six major puzzles in international economics.

${ }^{3}$ Papers that have been written on internal migration in other countries include: Congdon (2010), Poncet (2006), Andrienko and Guriev (2004), Mueser (1988), and Flowerdew and Aitkin (1982). Of these, only Poncet (2006) examines a border effect on rural to urban migration in China during the $1985-95$ period.

${ }^{4}$ Excluding the territories, there are 73 economic regions in Canada as defined by Statistics Canada. For this analysis, however, we collapse several regions around Montreal, Quebec as they, in our judgment, are a single labour market. See Appendix A for a listing of the 69 remaining economic regions.

${ }^{5}$ For example, the economic region of Ottawa includes five census divisions. Decisions to move between these five census divisions may reflect the desire to change homes rather than a response to economic factors.
} 
intra-national border effect but it also allows us to control for unobserved heterogeneity using panel data models with fixed effects. In fact, one of the innovations of this paper is the use of Poisson pseudo-maximum likelihood and negative binomial fixed effect regression models in the aggregate migration context, which allow us to appropriately handle count data with over-dispersion and control for unobserved heterogeneity. In addition, the richness of our dataset, contributes to this literature by improving variable measures and by adding several new covariates.

In all our model specifications, we find evidence of a border effect. The regression results also suggest that differences in employment rates, household income and language are associated with aggregate migration. We find some evidence that distance may be becoming less of a barrier to Canadian migration over time.

The rest of the paper is organized as follows: Section 2 describes the model and data. Section 3 discusses the selection of the most appropriate model and describes the results. Section 4 concludes.

\section{Empirical Methodology and Data}

\section{The Gravity Model}

Over the last few decades there has been growing body of research investigating the determinants of migration, which has given rise to two strands of literature. One literature examines the factors that influence individuals to migrate (Finnie 2004, Audas and McDonald 2003, Osberg et al. 1994). The second strand, and the area of this study, is concerned with explaining aggregate migration flows, often using a gravity model framework. ${ }^{6}$

The roots of the gravity model in economics lie in the trade literature. ${ }^{7}$ Under such models, the volume of trade is estimated to be positively associated with the economic size of trading partners and inversely related to the distance between them. When adapted to migration, the basic gravity model suggests that gross migration is positively related to the size of the origin and destination populations, and negatively associated with the distances that separate them. Abstracting from functional form, gross migration can be represented as:

$$
M_{i j}=\mathrm{F}\left(\ln P o p_{i}, \ln P o p_{j}, \ln D_{i s t}{ }_{i j}\right)
$$

\footnotetext{
${ }^{6}$ For surveys of this literature, see Stillwell (2005), Zimmermann and Bauer (2002) and Greenwood (1997).

${ }^{7}$ One of the first empirical papers in this literature is Pöyhönen (1963). There is now a large literature using gravity models to understand trade flows which includes: Millimet and Osang (2005), Anderson and Wincoop (2003) and Wall (2000).
} 
where $F$ represents the distribution function to be specified below and $M_{i j}$ equals the total number of Canadians who moved from economic region $i$ to economic region $j$ between two Census periods. We use the size of the population in the origin, $P_{0} p_{i}$, as a proxy for the pool of potential movers, and population in the destination, Pop $_{j}$, to proxy the "pull" of the destination region, which follows from the gravity law of migration whereby migrants tend to move to highly populated areas. Dist $t_{i j}$ is the distance in kilometres between the economic centers of economic regions $i$ and $j .{ }^{8}$ Distance is intended to proxy for the costs associated with migration, which may include: 1) transportationrelated costs (i.e. gasoline, moving van rentals, airfares), 2) psychic costs that arise from being apart from one's family and friends, and 3) costs related to gaining information on an unfamiliar location.

We extend the basic gravity model by including economic, cultural and geographical variables for origin and destination regions to produce our baseline model:

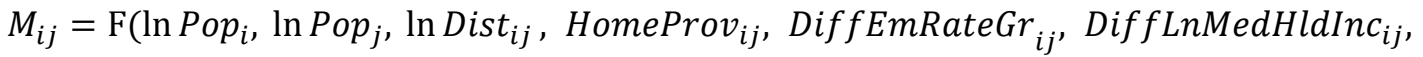

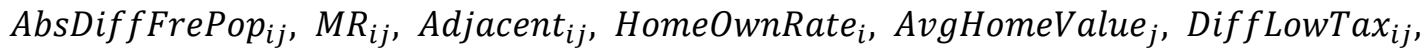

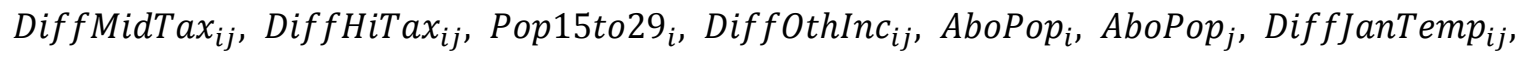
DiffRain $\left._{i j}, A T_{i}, Q C_{i}, P R_{i}, B C_{i}, A T_{j}, Q C_{j}, P R_{j}, B C_{j}, 2001,2006\right)$

where HomeProv $i j$ identifies flows between two economic regions in the same province. The results for this relationship will suggest the degree to which implicit and explicit barriers created by provincial borders, such as occupational licensing differences and set-up costs related to changing provinces (eg. new driver's licenses), act to deter migration. A border effect is calculated by taking the exponential of the coefficient estimate of the HomeProv $v_{i j}$ dummy variable.

We account for differences in job opportunities that may incent individuals to move using DiffEmRateGap ${ }_{i j}$, which equals the difference in the gap in employment rates for those aged 15 and old between two economic regions over the intercensal period. ${ }^{9}$ To control for the expected change in income from moving (Coulombe 2006, Helliwell 1997, Flowerdew and Amrhein 1989, Shaw 1985), we use the difference in the log of median household income, DiffLnMedHIdInc $c_{i j}$. As the literature finds

\footnotetext{
${ }^{8}$ Distances are measured using kilometres traveled from Google Maps.

${ }^{9}$ Unemployment rate differentials are a widely used measure (Coulombe 2006, Helliwell 1996, Helliwell 1997). However, some argue that unemployment rates are not necessarily the most appropriate measure since the unemployed represent only a relatively small percentage of the labor force and an even smaller percentage of the population (Greenwood 1997).
} 
evidence that language difference influence migration (Helliwell 1997, Flowerdew and Amrhein 1989), we account for French language effects by including AbsDiffFrePop $p_{i j}$, the absolute difference between regions in the percentage of the population that is francophone.

Anderson and Wincoop (2003) suggest that trade models that do not control for multilateral resistance suffer from omitted variable bias. One of the contributions of this paper to the migration literature is to include a measure of multilateral resistance, $M R_{i j}$, to capture the idea that migration does not only depend on the distances between two regions but also the distances from these regions to all other regions ${ }^{10,11}$ The highest value of multilateral resistance is Toronto-Lower Mainland Southwest (Vancouver) while one of the lowest is Winnipeg-Interlake. Adjacent ${ }_{i j}$ is used to identify flows between bordering economic regions ${ }^{12}$ (Helliwell 1997, Flowerdew and Amrhein 1989).

HomeOwnRate $_{i}$ captures costs associated with selling a home that may act as a disincentive to out-migration (Henley 1998, Oswald 1996), and AvgHomeValue ${ }_{j}$ controls for the effect of housing costs and potentially also the cost of living in the destination. Based on work by Day and Winer (2006), we use DiffLowTax $i j$, DiffMidTax $i j$ and DiffHiTax ${ }_{i j}$ to control for provincial differences in marginal income tax rates.

Younger people are more likely to move since they have a longer period to accrue benefits from migration and generally have fewer job and family ties (Greenwood 1975) ${ }^{13}$, and as such we use Pop15to19 to control for the percentage of the population in the origin that is aged 15 to 29 .

DiffOthInc $_{i j}$ is the differences in the percentages of total income that is other non-labour income used to identify retirees collecting pensions to control for retired Canadians moving to popular retirement locations. ${ }^{14}$ As aboriginal communities are very heterogeneous and many aboriginals belong to particular reserves, few aboriginals out-migrate, and due to cultural differences there is little inmigration to regions that are predominantly aboriginal. To take these factors into account we include variables $A b o P o p_{i}$ and $A b o P o p_{j}$ to control for the proportion of self-identified aboriginals in both the origin and destination populations.

We use DiffJanTemp ${ }_{i j}$ and DiffRain ${ }_{i j}$ to control for difference in average January temperatures and average annual rain days respectively (data from Environment Canada 2011) as others have

\footnotetext{
${ }^{10}$ In a sense, this can be thought as controlling for the opportunity cost for a given migration decision.

${ }^{11}$ As in Dolman (2008): $M R=\left(\right.$ ln Dist $_{i j}-\frac{1}{2} \sum_{k} \theta_{k} \ln$ Dist $_{i k}-\frac{1}{2} \sum_{k} \theta_{k} \ln$ Dist $\left._{k j}\right)-\left(\frac{1}{2} \sum_{k} \theta_{k} \ln\right.$ Dist $_{i k}+\frac{1}{2} \sum_{k} \theta_{k} \ln$ Dist $_{k j}-\sum_{l} \sum_{k} \theta_{l} \theta_{k} \ln$ Dist $\left._{l k}\right)$ where $\theta_{k}$ weights the distances and is equal to the share of total Canadian population in ER $k$.

${ }^{12}$ In order to be considered adjacent regions, two regions must be connected by a costless road. Although there is a bridge connecting PEI and the economic region of Moncton-Richibucto in NB, they are not considered adjacent regions because the connecting bridge charges a toll.

${ }^{13}$ Coulombe (2006) finds that the reaction of migrants to cyclical economic shocks is mainly seen among those aged $18-24$.

${ }^{14}$ This variable is highly correlated with the percentage of the population over the age of 65 . Using this instead, does not alter the results.
} 
suggested that climate may be associated with increased in-migration (Graves 1980, Renas and Kumar 1983, Glaeser and Tobio 2007). Finally, regional origin and destination dummy variables, $A T_{i j}, Q C_{i / j}, P R_{i / j}$ and $B C_{i / j}$ (Ontario as the base) are used to capture regional differences and time dummies, 2001 and 2006 (1996 is base), are used to control for changes over time that may affect all flows.

Table 2 presents a list of all the variables included in the analysis and their definitions, and Table 3 presents the mean, standard deviation and the expected sign for each.

\section{Model Specification}

Despite the popularity of using OLS and a log-normal model to understand migration in Canada ${ }^{15}$, it is not appropriate in this analysis. The issue is that our dependent variable, gross migration, follows a count data process which has many flows equal to zero and the log of these zero flows are undefined. ${ }^{16}$ Chart 2 presents the frequency distribution of gross migration for flows between economics regions up to 1,000 individuals, which represent over $90 \%$ of all observations, and shows that there is a lot of dispersion in gross migration. A large proportion of economic region pairs, roughly 23 per cent, have zero migration. The mean number of migration is 476.5 and the standard deviation is 2,046 . The large number of zeros combined with many small flows and the presence of very large flows is typical of a count data process.

A commonly suggested solution to handle outcome variables with many zeros is to transform them by a small amount so that they are defined (e.g. $\left.\log \left(M_{i j}+1\right)\right)$. However, it has been pointed out that this will lead to inconsistent estimators (Santos Silva and Tenreyro 2006) and when there are many zeros, (Flowerdew and Aitkin 1982) small differences in the amount of adjustment chosen can cause large differences in the estimated coefficients and explanatory power of the model. Given these limitations, we turn to regression models specifically designed to handle count data.

A natural alternative to the log normal model is the Poisson model. The Poisson model involves taking the exponential of the independent variables, therefore ensuring that the conditional mean of $M_{i j}$ is non-negative. Under the Poisson model it is assumed that there is a constant probability, $P_{i j}$, that any individual will move from economic region $i$ to economic region $j$, and that individuals' movements are independent of each other (Flowerdew and Aitkin 1982). Given these assumptions are met, the number of individuals recorded as moving from $i$ to $j$ will have a Poisson

\footnotetext{
15 Papers that have examined aggregate migration flows with OLS have used data aggregated to a relatively high level such as the province or city (e.g. Helliwell 1997, Shaw 1986) where there are no zeroes, few small flows and as many large flows.

${ }^{16}$ For a comprehensive description of this and other reasons why OLS is not appropriate for this analysis see Flowerdew and Amrhein (1982).
} 
distribution with mean $\mu$, and the probability that $m$ individuals are recorded as migrating is (Flowerdew and Aitkin 1982):

$$
\operatorname{Pr}\left(M_{i j}=m \mid \mu\right)=\frac{e^{-\mu_{i j}} \mu_{i j}{ }^{m}}{m !}, \mathrm{m}=0,1,2, \ldots
$$

One of the other underlying assumptions of the Poisson model is equi-dispersion, that is, the conditional variance of the dependent variable is equal to its conditional mean. It also assumes that the mean $\mu_{i j}$ is exponentially linked to a linear combination of the explanatory variables, $X_{i j}$ :

$$
\mu_{i j}=\exp \left(\rho_{0}+\beta^{\prime} X_{i j}\right)
$$

where (4) describes a Poisson regression model. In this analysis, $X_{i j}$ is a vector that includes the basic gravity model variables related to population and distance as well as other explanatory variables outlined above.

The Poisson model assumption of equi-dispersion is often not met because the conditional variance is larger than the conditional mean, referred to as over-dispersion. In order to estimate gravity equations in the presence of over-dispersion, Santos Silva and Tenreyro (2006) recommend using Poisson pseudo-maximum-likelihood (PPML) estimation techniques, which does not assume equi-dispersion. PPML is optimal when the conditional variance is proportional (though not necessarily equal) to the conditional mean, and even if the two are not proportional, the PPML will still be consistent. For such models, the estimation of the mean is the same as under a Poisson model but the variance is estimated using robust standard errors.

An alternative to the PPML model is the negative binomial (NB) model. It is a modified Poisson model that addresses over-dispersion by allowing for additional variance in $M_{i j}$ by multiplicatively introducing randomness to the Poisson model. This can be achieved by replacing $\mu$ by $\mu v$ in (3) above, where $v$ is a random variable:

$$
\operatorname{Pr}\left(M_{i j}=m \mid \mu, v\right)=\frac{e^{-v_{i j} \mu_{i j}} v_{i j} \mu_{i j}{ }^{m}}{m !}, \mathrm{m}=0,1,2, \ldots
$$

In the commonly used special case, $e^{v}$ follows a Gamma $(1 / \alpha, \alpha)$ distribution, where $\alpha$, often referred to as the dispersion parameter, is responsible for adding additional variance to the model. This 
Gamma distribution has a mean of 1 and variance of $\alpha$. The probability mass function for the negative binomial distribution can be written as (Cameron and Trivedi 2010):

$$
\operatorname{Pr}\left(M_{i j}=m \mid \mu, v\right)=\frac{\Gamma\left(\alpha^{-1}+m\right)}{\Gamma\left(\alpha^{-1}\right) \Gamma(m+1)}\left(\frac{\alpha^{-1}}{\alpha^{-1}+\mu_{i j}}\right)^{\alpha^{-1}}\left(\frac{\mu_{i j}}{\mu_{i j}+\alpha^{-1}}\right)^{m}
$$

where $\Gamma$ is the Gamma function. The negative binomial regression model is a modified version of the Poisson regression model and can be written as:

$$
\mu_{i j}=\exp \left(\rho_{0}+\beta^{\prime} X_{i j}+v_{i j}\right)
$$

Estimation of the negative binomial regression model will produce an estimate for $\alpha$. A larger $\alpha$ implies larger dispersion, whereas $\alpha$ equal to 0 corresponds to the Poisson model. ${ }^{17}$

Note also that the results of negative binomial models depend on the scale of dependent variable. In an unpublished paper, Bosquet and Boulhol (2010) point out that as the scale increases and the dependent variable takes on a lower value, the dispersion parameter of the negative binomial model decreases. As a result, the results of the negative binomial model approach those of the Poisson. Conversely, when the scale decreases, the negative binomial estimates approach the results of an equivalently specified model with a Gamma distribution.

\section{Estimation Issues}

While our baseline models may estimate significant relationships between explanatory variables and migration, caution must be taken in interpreting such results as causal as they may suffer from endogeneity bias, either due to simultaneity or unobserved heterogeneity, or both. Simultaneity bias may arise in migration studies if end-of-period explanatory variables are used to explain migration over a particular period (Greenwood 1975). If the period of time is lengthy, migration itself can affect the end-of-period levels of these variables. To avoid this potential bias, we use beginning-of-period values for most of the time-variant variables. The only exception is DiffEmRateGap $p_{i j}$, which measures the change in the employment rate gap between the two regions over the period.

\footnotetext{
${ }^{17}$ Zero-inflated Poisson and negative binomial models as well as hurdle models were also considered but it is not clear that the gross migration flows exhibit the data generating processes described by such models, and therefore they were deemed inappropriate for this analysis.
} 
In order to minimize bias due to unobserved heterogeneity, we examine two fixed effects models specifications. ${ }^{18}$ The first is a PPML model with traditional fixed effects that uses dummy variables to control for province-specific effects for the origins and destinations separately, which enter our baseline Poisson regression model $\mathrm{as}^{19}$ :

$$
\mu_{i j}=\exp \left(\ldots+\beta_{1} \operatorname{ProvFE}_{i}+\beta_{2} \operatorname{ProvFE}_{j}\right)
$$

PPML models with fixed effects for provincial pairs and pairs of economic regions were considered but are not appropriate. In a PPML model with provincial pairs fixed effects, the border variable will be perfectly collinear with the linear combination of provincial pairs and drops out of the estimated model. The same occurs in PPML models with economic region-pair fixed effects. Also, in such models, since the data have 490 economic region pairs with zero migration for all three intercensal periods (for a total of 1470 observations), there is no variation in the dependent variable within the group, and these observations drop out of the regression analysis. The resulting sample is no longer representative of the total Canadian population of economic regions, decreasing the external validity of the results. The change in sample also makes it difficult to compare the performance of this model with others.

Negative binominal models with traditional fixed effects (i.e. with origin and destination province dummy variables, provincial-pair dummy variables and origin and destination economic region dummy variables) were also considered. However, such models, as well as most other nonlinear fixed effects models (except Poisson fixed effects models), suffer from the incidental parameters problem (IPP). The IPP arises in non-linear analyses with short panels where the unit effects cannot be consistently estimated due to a small number of observations per unit (Cameron and Trivedi 2010). Since the unit effects are jointly estimated with the model parameters, inconsistent estimates for the unit effects may lead to inconsistent estimation of the other parameter coefficients (Cameron and Trivedi 2010). Some argue that the inconsistency may not be large, but nevertheless it is present, and therefore the results from such models are not considered appropriate.

\footnotetext{
${ }^{18}$ Random-effects models are similar to FEs models in that they also assume an unobserved unit effect. However, unlike FEs models, they assume that the unobserved unit effect is uncorrelated with the observed explanatory variables, a strict assumption that is often difficult to make. In results not shown, we ran the random-effects model equivalent of our preferred model below. The Hausman test statistic is large (123.05) and highly statistically significant. This suggests that the random-effects model is not consistent, and that the conditional FEs negative binomial is the preferred estimator.

${ }^{19}$ Note that this is not a "traditional" panel set-up since it does not use a time element.
} 
With negative binomial models, an alternative to traditional fixed effects are conditional fixed effects models. While traditional fixed effects control for unobserved heterogeneity common to particular units that is assumed to be correlated with the model's explanatory variables, under conditional fixed effects, "the fixed effects apply to the distribution of the dispersion parameter, and not to the $x B$ term in the model" (Stata7 2001). More specifically, recall that in order to introduce additional dispersion into the Poisson model, a random variable, $v$, was added to create the negative binomial model. The random variable is commonly assumed to be Gamma distributed with variance $\alpha$, which is assumed to be constant for all units. Under the conditional fixed effects model this dispersion parameter is allowed to vary across groups but is the same for units in the each group $i$, therefore becoming $\alpha_{i}$. This suggests that the probability mass function in (6) now includes a dispersion parameter specific to each group:

$$
\operatorname{Pr}\left(M_{i j}=m \mid \mu, v\right)=\frac{\Gamma\left(\alpha_{i}^{-1}+m\right)}{\Gamma\left(\alpha_{i}^{-1}\right) \Gamma(m+1)}\left(\frac{\alpha_{i}^{-1}}{\alpha_{i}^{-1}+\mu_{i j}}\right)^{\alpha_{i}^{-1}}\left(\frac{\mu_{i j}}{\mu_{i j}+\alpha_{i}^{-1}}\right)^{m}
$$

The conditional fixed-effects model is calculated by conditioning on total counts of the dependent variable. When conditioned on total counts, the likelihood function for each unit will factor out the dispersion parameter $\alpha_{i}$ for each group (Hausman, Hall and Griliches, 1984). Unlike traditional fixed effects in OLS, since conditional fixed effects negative binomial models account for heterogeneity in the variance and not the mean, these models are able to estimate the coefficients of time-invariant regressor. We use a conditional fixed effects model to control for provincial-pair specific effects ${ }^{20}$ :

$$
\mu_{i j}=\exp \left(\ldots v_{\text {ProvPair }_{i j}}\right)
$$

We also considered a negative binomial model with conditional fixed effects for economic regionpairs, however, similar to the PPML model with economic region-pair fixed effects, 490 observations

\footnotetext{
${ }^{20}$ Also note that this is not a "traditional" panel set-up since it does not use a time element.
} 
with zero flow in all three intercensal periods drop out of the regression analysis. ${ }^{21}$ For the same reasons, such results are not preferred. ${ }^{22}$

It is important to emphasize, as pointed out in Allison and Waterman (2002), Greene (2007) and Guimarães (2008), that the conditional fixed effects negative binomial model is not a "true" fixedeffects model. Guimarães (2008) shows that, only under a very specific set of assumptions, do conditional fixed effects models eliminate individual heterogeneity. In particular, "there is a specific functional relation between the individual fixed effects and the individual over-dispersion parameter" that must be satisfied (Guimarães 2008). As such, the conditional fixed effects model does not account for heterogeneity in the mean, the conditional mean is still homogenous, and therefore may suffer from an omitted variable problem (Greene 2007).

\section{Data}

The main sources of data for this analysis are Statistic Canada's 1991, 1996, 2001 and 2006 Censuses with the data aggregated to the economic region level. Excluding the territories, there are 69 economic regions in our sample. ${ }^{23}$ For this analysis, each observation represents a pair of economic regions, giving 4692 (69 X 68) pairs of flows each intercensal period. With three intercensal periods per pair, there are 14,076 total observations. We use the Census data to create the dependent variable (gross migration) as well as the explanatory variables related to demographic, economic and cultural factors such as population sizes, the employment rate and the size of the French-speaking population. Other sources were used to create variables related to distance (Google Maps), marginal tax rates (Canada Revenue Agency 2011) and weather (Environment Canada 2011). To create the distance and weather variables, we identify the "economic center", which was typically the largest city or town, for each economic region. ${ }^{24}$

\footnotetext{
${ }^{21}$ Unlike the Poisson model, the HomeProv ${ }_{i j}$ variable can be estimated in these models. As a potential solution to having a many zeroes, we transformed gross flows by small amounts (i.e.: $\left.M_{i j}+0.01 / 0.1 / 1 / 10 / 100\right)$. While there is some stability in results across the sizes of adjustment, due to the known problems with such adjustments in log normal models, we do not emphasize these results (but are available on request).

${ }^{22}$ Note that there is no conditional FEs model using origin and destination FEs (at the province or ER level) separately, since, to our knowledge, it is not possible to include separate origin and destination conditional FEs using the xtnbreg command in Stata or any other software.

${ }^{23}$ With the territories excluded, there are actually 73 economic regions remaining. However, elevated migration values and anecdotal information led us to believe that many of the flows in the five economic regions around Montreal were due to differences in factors unrelated to labour markets, language or demographics. As such, a decision was made to collapse these five regions into one economic region.

${ }^{24}$ For example: St. John's for the Avalon Peninsula (NL), Rimouski for Bas-Saint-Laurent (QC) and Vancouver for Lower Mainland-Southwest (BC).
} 


\section{Model Selection and Empirical Results}

\section{Model Selection}

Table 4 presents the results for the PPML and negative binomial models described in Section 2.

Models I and III use the baseline specification with PPML and negative binomial distributions

respectively. Model II is a PPML model with traditional fixed effects that identify origin and destination

provinces. The column for Model IV presents the results for a negative binomial model with

conditional fixed effects for provincial-pairs. Note that Models II and IV are not "traditional" panel set-

ups since they do not have a time element. Also, the negative binomial conditional fixed effects model

produces a coefficient estimate for the border variable, since, as described in section 2, such models

account for heterogeneity in the variance, not the mean, and as such produce coefficient estimates for variables that are constant within fixed effects groups. ${ }^{25}$

The results in Table 4 shows that the AIC and BIC measures decrease from left to right, and suggest that the negative binomial model with conditional fixed effects in Model IV provides the best fit. This is despite the fact that the conditional fixed effects negative binomial model is not a "true" fixed effects model. Although the results from Model IV provide the best fit according to the information criteria, Santos Silva and Tenreyro (2006) recommend using PPML models to estimate gravity models. Based on these two influences, we present and compare the results from both Model IV as well as Model II (since it has the lower AIC and BIC of the two PPML models). In many cases, the coefficient estimates for the two models are very similar, and where they are not, the differences are pointed out. ${ }^{26}$

\section{Empirical Results}

\footnotetext{
${ }^{25}$ The results for several other specifications that were deemed inappropriate in Section 2 are available in Appendix B. Despite the IPP and that time-invariant variables (such as the border variable) cannot be estimated, we also tried to estimate a traditional fixed effects negative binomial model with economic region pair effects. However, the model will not run. This is not surprisingly given that Cameron and Trivedi (1998) argue that traditional fixed effects models may be impractical if the total number of regressors exceeds software restrictions. In this specification, there would be more than 4692 regressors as there are 4692 pairs of economic regions.

${ }^{26}$ Appendix $C$ presents the results of the same specifications but with the dependent variable, gross migration, scaled by 100 . While the coefficient estimates and standard errors of the PPML models do not change, the results for the negative binomials do (in particular the size of the HomeProv $i j$ variable, which is puzzling). Many of the NB coefficient estimates approach the PPML estimates. Also, the AIC and BIC measures have declined for all the models, and especially the PPML models, and are much more similar. When the scale is increased to 1000 , the negative binomial model with fixed effects does not run.
} 
In Table 4, among the basic gravity model variables, the estimated coefficient for logged destination population in Models II and IV suggests that a one per cent increase in the destination population is related to an increase in migration of 0.83-0.84 per cent. Similarly, the same increase for the origin population is associated with an increase in migration of 0.70 per cent in both our preferred models. In terms of the estimated impact of our distance variable, a one per cent increase in distance between two economic regions is related to a decrease in migration that ranges from 0.23-0.43 per cent in Models II and IV. These estimates are slightly above the upper range for distance elasticities of -0.1 to 0.2 outlined in Greenwood (1997). However, they are considerably smaller than the coefficient estimate of -0.98 from a simple negative binomial regression using no fixed effects and only variables on population sizes, distance and the border (results not shown but available upon request).

In these specifications, we also include variables that interact logged distance with dummy variables for the second and third intercensal periods (the first period is the base). Neither of the coefficient estimates for these interaction terms is statistically significant in Model II. Conversely, in Model IV, the coefficient estimates are positive and statistically significant, suggesting a weaker relationship between distance and migration in the latter two periods. Furthermore, when the equality of these two interactions terms is tested, it is rejected. Given the size of these estimates, this suggests that the relationship in the third intercensal period is even weaker than in the second period. This finding is consistent with recent advancements in communication-related technology, which make it easier to migrate. Not only do the Internet (and applications such as Skype) and cell phones reduce the psychic costs related to moving away from one's family or hometown but they also lower the cost of obtaining information that is helpful in the decisions and processes involved in migrating. Greenwood (1997) points to several studies on U.S. internal migration that have also found declines in the distance elasticities over time.

The coefficient estimates for the HomeProv $i$ variable in both models Models II and IV are positive and statistically significant but differ in magnitude and precision. The estimated coefficient in Model IV (II) is statistically significant at 10 (1) per cent and suggests that the absence of a provincial border is related to migration flows that are, on average, 10 (98) per cent higher. Although the coefficient estimate in Model IV is less precise and more sensitive to the inclusion of other explanatory variables than the estimate in Model II, it is also the more conservative estimate.

Helliwell (1997) calculates the effect of the Canada-US border on migration to be 100 , which suggests that for every resident in a Canadian province who was born in a U.S. state, there are 100 residents who were born in some other Canadian province (excluding Quebec). The lack of an 
international border increases migration by a factor of 100. In our analysis, we estimate that migration from an economic region within the same province would be greater than out-of-province migration by a factor of 1.11 to 2.66 , based on results from Models IV and II respectively. This implies that, all else held constant, for every 100 out-of-province migrants in a particular economic region, there are 111 to 266 migrants that are from a different economic region in the same province. It is not surprising that this estimate is much lower than the effect noted in Helliwell (1997) as they represent effects of borders at different levels, one international and the other intra-national. Also, the estimated border effect in Helliwell (1997) may be biased upward as it is based on an analysis that does not include several important variables such as multilateral resistance nor fixed-effects.

Among the other key independent variables, DiffEmRateGap ${ }_{i j}$ and DiffLnMedHIdInc ${ }_{i j}$ are also estimated to have a positive and statistically significant relationship with migration flows in both Models II and IV, while the coefficient estimates for AbsDiffFrePop ${ }_{i j}$ and Border ${ }_{i j}$ are negative and statistically significant in both models. Rather than present the marginal effects for these coefficient estimates, some have suggested (Cameron and Trivedi 1998) that a similarly intuitive and helpful presentation of the results is to compare the relative sizes of the estimates. ${ }^{27,28}$

First, we examine the estimated coefficients for the two labour market variables. The estimates are very similar in both Models II and IV, ranging 0.0235-0.0245 for DiffEmRateGap ${ }_{i j}$ and

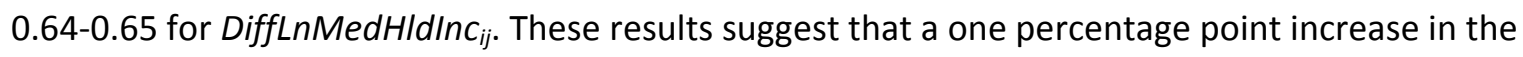
employment rate gap is associated with a 2.35-2.45 increase in migration, while a one per cent increase in the difference of logged median income is related to a 0.64-0.65 increase in migration. Using these results, their relative sizes suggest that in order to offset a one percentage point increase in the employment rate gap in the destination, median household income would have to be 3.67-3.77 per cent higher in the origin. To make this more concrete, take the case where the median income in the destination region equals the average of median household incomes across all economic regions $(\$ 44,805)$, this result implies that the median income in the origin would need to be $\$ 1,223-\$ 1,664$ higher (or $\$ 46,028-\$ 46,469$ ) to offset the increase in the employment rate gap.

In Models II and IV, the coefficient estimates for AbsDiffFrePop $i j$ suggest that a one percentage point increase in the difference in the proportion of the populations that is French-speaking is associated with a 1.52-1.64 per cent decrease in the migration between economic regions. We compare these coefficient estimates to the two labour market variables. When comparing French-

\footnotetext{
${ }^{27}$ When calculated, the marginal effects for Model IV were very small (available upon request).

${ }^{28}$ Keep in mind that the estimated coefficients differ in terms of units of measure (e.g. rates vs. levels), and therefore caution must be exercised when interpreting the necessary increase or decrease needed in one variable to offset a change in the other variable.
} 
speaking and employment rate gap coefficient estimates, the ratio suggests that a $0.62-0.70$ percentage point increase in the employment rate gap is needed to offset the disincentive to migrate created by a one percentage point difference in the percentage of the population that is Frenchspeaking. The same change in the percentage of those French-speaking would be equivalent to a 2.342.57 per cent decrease in median household income. While the impact of a unit change in the Frenchspeaking variable is small compared to these labour market variables, given that the average dispersion between two economic regions in this variable is large (30.8 per cent), the total effect will, on average, also be large. To offset the average difference in French-speaking populations would require a 19-22 percentage point increase in the employment rate gap and a 72-79 per cent increase in median household income.

\section{Conclusion}

Understanding the factors that drive and inhibit aggregate migration flows is crucial for policy makers to assess changes in growth and inflation. The influence of the border on migration is important in itself but recent research suggests that the degree to which borders inhibit migration may also matter for trade. Despite all of this, little work has looked at the effect of borders on intra-national migration in Canada. To date, research on aggregate migration in Canadian has either focused on migration at the provincial level, which cannot include a provincial border dummy variable, or at the sub-provincial level but does not control for borders. Using Census data at the economic region level, we address this gap in the literature by estimating a provincial border effect. This is also the first paper on aggregate migration to use Poisson pseudo-maximum likelihood and negative binomial fixed effects models -models that allow us to handle count data with over-dispersion as well as control for unobserved heterogeneity. With our rich dataset, we also contribute to the literature by improving variable measures and by adding several new covariates.

Across several different regression model specifications, we find evidence of a border effect. The estimates suggest that, on average, migration within the same province may be 10 to 98 per cent higher than migration across provinces, all else held constant. The results also indicate that differences in employment rates, incomes and language matter. Consistent with evidence from the U.S., we also find that the negative effect of distance on migration may be decreasing over time.

Overall, the results from this analysis suggest that provincial borders are one of many factors influencing migration in Canada. While the presence of a border effect implies that institutional 
barriers to interprovincial mobility remain, the size of the effect is estimated in one model to be relatively small. Nonetheless, these findings provide evidence that there may be room to modify provincial regulations to decrease barriers to migration in Canada and facilitate macroeconomic adjustment.

Given recent advancements in communication-related technology and transportation, it is not surprisingly that we find evidence suggesting that distance is becoming less of a barrier to migration over time. Such results are also consistent with a growing trend in long distance commuting. Taken together, these trends suggest that understanding the extent to which commuting is a substitute for moving may be a fruitful direction for future research on migration. 


\section{References}

Allison, P. D. and R.P. Waterman. 2002. "Fixed-Effects Negative Binomial Regression Models." Sociological Methodology 32: 247-265.

Anderson, J., and E. van Wincoop. 2003. "Gravity with gravitas: a solution to the border puzzle." American Economic Review 93: 170-92.

Andrienko, Y. and S. Guriev. 2004. "Determinants of interregional mobility in Russia: Evidence from panel data." Economics of Transition 12 (1): 1-27.

Audas, R. and J. McDonald. 2003. "Employment Insurance and Geographic Mobility: Evidence from the SLID." SRDC Working Paper Series 03-03. Ottawa: Statistics Canada.

Bosquet, C. and H. Boulhol. 2010. "Scale-Dependence of the Negative Binomial Pseudo-Maximum Likelihood Estimator." Universités d'Aix Marseille II et III, Document de Travail no. 2010-39.

Cameron, A.C. and P.K. Trivedi. 2010. Microeconometrics Using Stata. Texas: Stata Press.

Canada Revenue Agency (1996) http://www.cra-arc.gc.ca/formspubs/prioryear/t1/1996/menu-e.html. (Last accessed June 11, 2011)

Canada Revenue Agency (2001) http://www.cra-arc.gc.ca/tx/ndvdls/fq/2001 rt-eng.html. (Last accessed June 10, 2011)

Canada Revenue Agency (2006a) http://www.cra-arc.gc.ca/tx/ndvdls/fq/2006 rt-eng.html. (Last accessed June 10, 2011)

Canada Revenue Agency (2006b) http://www.statcan.gc.ca/pub/68-213-s/2006000/t/4067414-eng.htm. (Last accessed June 11, 2011)

Congdon, P. 2010. "Random-effects models for migration attractivity and retentivity: a Bayesian methodology." Journal of the Royal Statistical Society 173, Part 4: 755-774.

Coulombe, S. 2006. "Internal Migration, Asymmetric Shocks, and Interprovincial Economic Adjustments in Canada." International Regional Science Review 29(2): 199-223.

Day, K. M., and S. Winer. 2006. "Policy-induced internal migration: An empirical investigation of the Canadian case." International Tax Public Finance 13: 535-564.

Environment Canada. 2011. National Climate Data and Information Archive, Canadian Climate Normals, http://climate.weatheroffice.gc.ca/climate normals/index e.html. Last accessed: May 30, 2011.

Finnie, R. 2004. "Who moves? A Panel Logit Model Analysis of Inter-Provincial Migration in Canada". Applied Economics 36: 1759-1799.

Flowerdew, R. and M. Aitkin. 1982. "A method of fitting the gravity model based on the Poisson distribution." Journal of Regional Science 22(2): 191-202. 
Flowerdew, R. and C. Amrhein. 1989. "Poisson Regression Models of Canadian Census Division Migration Flows." Papers of the Regional Science Association 67: 89-102.

Foot, D. and W. Milne. 1984. "Net Migration Estimation in an Extended, Multiregional Gravity Model." Journal of Regional Science 24(1): 119-133:

Glaeser, E. and K. Tobio. 2007. “The Rise of the Sunbelt.” NBER Working Paper Series 13071

Graves, P. 1980. “Migration and Climate.” Journal of Regional Science 20(2): 227-237.

Greene, W. 2007. "Fixed and Random Effects Models for Count Data." Working Papers 07-15, New York University, Leonard N. Stern School of Business, Department of Economics.

Greenwood, M. J. 1997. "Internal Migration in Developed Countries." in Handbook of Population and Family Economics, eds. M.R. Rozenweig and O. Stark, Elsevier Science. New York: Elsevier.

Guimarães, P. 2008. “The fixed effects negative binomial model revisited.” Economics Letters 99(1): 63-66.

Hausman, J. B. Hall, and Z. Griliches. 1984. "Econometric Models for Count Data with an Application to the Patents-R\&D Relationship." Econometrica 52(4): 909-938.

Helliwell, J. 1997. “National Borders, Trade and Migration.” Pacific Economic Review, 2(3): 165-185.

Henley, A. 1998. "Residential Mobility, Housing Equity and the Labour Market." The Economic Journal, Vol. 108 (March), pp. 414-427.

Hilbe, J. 2011. Negative Binomial Regression. Cambridge: Cambridge University Press.

Lefebvre, M. and S. Poloz. 1996. "The Commodity-Price Cycle and Regional Economic Performance in Canada." Bank of Canada Working Paper 96-12.

Long, J. and J. Freese. 2003. Regression Models for Categorical Dependent Variables Using Stata. Texas: Stata Press.

McCallum, J. 1995. "National borders matter: Canada-U.S. regional trade patterns". American Economic Review, 85: 615-23.

Millimet, D. and T. Osang. 2007. "Do State Borders Matter for U.S. Intranational Trade? The Role of History and Internal Migration." Canadian Journal of Economics 40(1): 93-126.

Mueser, P. 1988. "The Spatial Structure of Migration: An Analysis of Flows Between States in the USA Over Three Decades." Regional Studies 23(3):

Obstfeld, M., and K. Rogoff. 2000. "The six major puzzles in international economics: is there a common cause?" In NBER Macroeconomics Annual 2000, ed. B.S. Bernanke and J. Rotemberg. Cambridge, MA: MIT Press.

Osberg, L., D. Gordon, and Z. Lin. 1994. "Inter-Regional Migration and Inter-Industry Labour Mobility in Canada: A Simultaneous Approach.” Canadian Journal of Economics 27(1): 58-80. 
Oswald, A. 1996. A Conjecture on the Explanation for High Unemployment in the Industrialized Nations: Part I. Warwick Economic Research Papers, No. 475.

Poncet, S. 2006. "Provincial migration dynamics in China: Borders, costs and economic motivations." Regional Science and Urban Economics, 36: 385-398.

Pöyhönen, P. 1963. "A Tentative Model for the Volume of Trade between Countries." Weltwirtschaftliches Archiv, Bd. 90: 93-100

Renas, S. and R. Kumar. 1983. "Climatic Conditions and Migration: An Econometric Inquiry." The Annals of Regional Science 17(1): 69-78.

Santos Silva, J.M.C. and S. Tenreyro. 2006. "The Log of Gravity." The Review of Economics and Statistics, 88(4): 641-658.

Shaw, R.P. 1986. "Fiscal versus Traditional Market Variables in Canadian Migration." The Journal of Political Economy 94( 3): 648-666

Simmons, J.W. 1980. "Changing Migration Patterns in Canada: 1966-71 to 1971-76." Canadian Journal of Regional Science, 3: 39-62.

StataCorp. 2001. Stata Statistical Software: Release 7.0. College Station, Texas: Stata Corporation.

Stillwell, J. 2005. "Inter-regional Migration Modelling: A Review and Assessment." $45^{\text {th }}$ Congress of the European Regional Science Association, Vrije Universiteit, The Netherlands.

Wall, H. J. 2009. "Gravity Model Specification and the Effect of the Canada-U.S. Border". Federal Reserve Bank of St. Louis Working Paper 2000-024A.

Wolf, Holger C. 2000. "Intranational home bias in trade." Review of Economics and Statistics, 82: 555-63.

Wooldridge, J. 2002. Econometric Analysis of Cross Section and Panel Data. Cambridge, Massachusetts: The MIT Press.

Zimmermann, K.F. and T.K. Bauer. 2002. The Economics of Migration. Cheltenham: Edward Elgar (eds), (4 vols). 
Table 1: Intra and Inter-provincial Migration Flows By Intercensal Period

\begin{tabular}{l|c|c|c}
\hline \hline & $1991-1996$ & $1996-2001$ & $2001-2006$ \\
\hline & & & \\
Total Population (in end period) & $28,353,196$ & $29,470,770$ & $31,061,360$ \\
& & & \\
Intra-provincial migration (flow in same province, $_{\text {different economic region) }}^{+}$ & $1,627,498$ & $1,672,290$ & $1,634,430$ \\
Inter-provincial migration (flow between different $_{\text {provinces) }^{+}}$ & $(5.74 \%)$ & $(5.67 \%)$ & $(5.26 \%)$ \\
\hline \hline
\end{tabular}

${ }^{\dagger}$ Migration as a share of total population is in parentheses. 
Table 2: Variable Names and Definitions

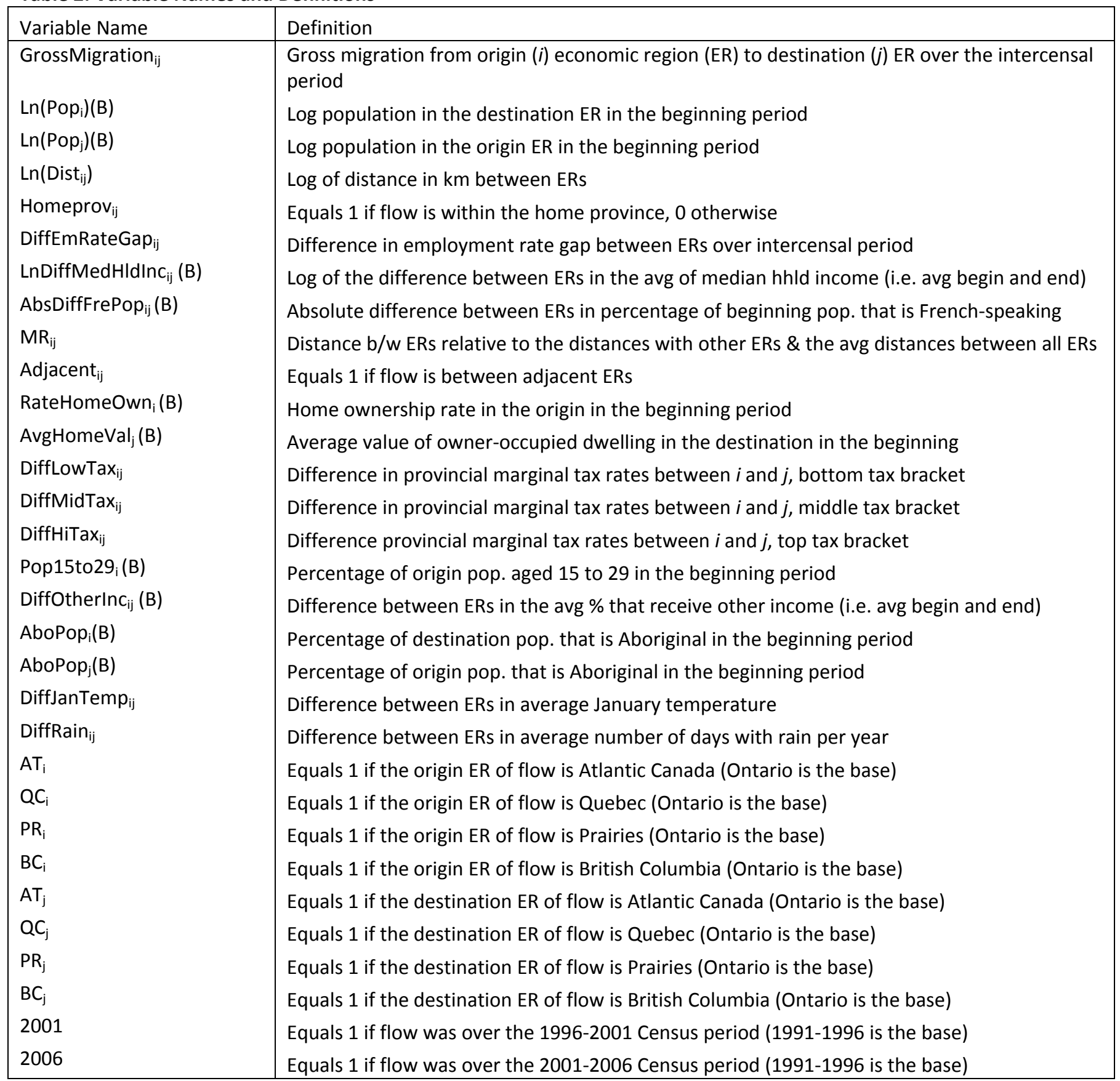


Table 3: Summary Statistics and Expected Direction of Effect

(Mean of each variable with standard deviation in parentheses)

\begin{tabular}{|c|c|c|c|}
\hline & $\begin{array}{c}\text { Mean } \\
\text { (standard } \\
\text { deviation) }\end{array}$ & Sign & Reason \\
\hline GrossMigration $_{\mathrm{ij}}$ & $\begin{array}{c}476.5 \\
(2046.2)\end{array}$ & $\mathrm{N} / \mathrm{A}$ & N/A \\
\hline $\operatorname{Ln}\left(\mathrm{Pop}_{\mathrm{i}}\right)(\mathrm{B})$ & $\begin{array}{c}12.22 \\
(1.049)\end{array}$ & + & Gravity, proxies pool of potential migrants \\
\hline $\operatorname{Ln}\left(\mathrm{Pop}_{\mathrm{j}}\right)(\mathrm{B})$ & $\begin{array}{c}12.22 \\
(1.049)\end{array}$ & + & Gravity, proxies "pull" \\
\hline $\operatorname{Ln}\left(\right.$ Dist $\left._{\mathrm{ij}}\right)$ & $\begin{array}{c}7.567 \\
(0.952)\end{array}$ & - & $\begin{array}{l}\text { Gravity (resistance): Moving and psychic } \\
\text { costs, lack of information }\end{array}$ \\
\hline HomeProv $_{i j}$ & $\begin{array}{c}0.11 \\
(0.313)\end{array}$ & + & $\begin{array}{c}\text { Lack of cultural, political or administrative } \\
\text { barrier }\end{array}$ \\
\hline DiffEmRateGap $_{\mathrm{ij}}$ & $\begin{array}{c}0 \\
(2.566)\end{array}$ & + & Proxy for job opportunities \\
\hline LnDiffMedHIdInc $c_{i j}(B)$ & $\begin{array}{c}0 \\
(0.229)\end{array}$ & + & $\begin{array}{l}\text { Proxy for higher expected future income } \\
\text { stream }\end{array}$ \\
\hline AbsDiffFrePop $_{\mathrm{ij}}(\mathrm{B})$ & $\begin{array}{c}30.82 \\
(38.80)\end{array}$ & - & Resistance due to language differences \\
\hline $\mathrm{MR}_{\mathrm{ij}}$ & $\begin{array}{c}0.544 \\
(1.064)\end{array}$ & - & $\begin{array}{c}\text { Resistance based on distance from paired } \\
\text { ER and distance to other ERs }\end{array}$ \\
\hline Adjacent $_{\mathrm{ij}}$ & $\begin{array}{l}0.0546 \\
(0.227)\end{array}$ & $+/-$ & $\begin{array}{c}\text { Closer than distance suggests vs. lack of } \\
\text { diversity in opportunities }\end{array}$ \\
\hline RateHomeOwn $(\mathrm{B})$ & $\begin{array}{c}69.47 \\
(9.133)\end{array}$ & - & Cost of selling an owned home \\
\hline AvgHomeVal $_{j}(B)(10,000 s)$ & $\begin{array}{c}10.20 \\
(4.513)\end{array}$ & - & Cost of housing/living \\
\hline DiffLowTax $_{\mathrm{ij}}$ & $\begin{array}{c}0 \\
(4.081)\end{array}$ & ? & \\
\hline DiffMidTax $_{\mathrm{ij}}$ & $\begin{array}{c}0 \\
(4.568)\end{array}$ & $?$ & \\
\hline DiffHiTax $_{\mathrm{ij}}$ & $\begin{array}{c}0 \\
(5.572)\end{array}$ & ? & \\
\hline Pct15to29i $(B)$ & $\begin{array}{c}21.10 \\
(2.391)\end{array}$ & + & Younger people are more likely to migrate \\
\hline DiffOtherlnc $c_{i j}(B)$ & $\begin{array}{c}0 \\
(4.384)\end{array}$ & + & $\begin{array}{c}\text { Identifies individuals with } \\
\text { pensions - proxy retirement destinations }\end{array}$ \\
\hline $\mathrm{AboPop}_{\mathrm{i}}(\mathrm{B})$ & $\begin{array}{c}8.17 \\
(0.152)\end{array}$ & $-/+$ & For avg Cdn, cultural barrier \\
\hline $\mathrm{AboPop}_{\mathrm{j}}(\mathrm{B})$ & $\begin{array}{c}8.17 \\
(0.152)\end{array}$ & - & For avg Cdn, cultural barrier \\
\hline DiffJanTemp $_{\mathrm{ij}}$ & $\begin{array}{c}0 \\
(7.947)\end{array}$ & + & Better physical environment \\
\hline DiffRain $_{\mathrm{ij}}$ & $\begin{array}{c}0 \\
(33.89)\end{array}$ & - & Poorer physical environment \\
\hline
\end{tabular}

Source: Statistics Canada Census (1991, 1996, 2001, 2006) 
Table 4: Poisson and Negative Binomial Results (dep var: gross flows)

\begin{tabular}{|c|c|c|c|c|}
\hline & \multicolumn{2}{|c|}{ Poisson } & \multicolumn{2}{|c|}{ Negative Binomial } \\
\hline & No $\mathrm{FE}^{\dagger}$ & O\&D Provs ${ }^{\dagger}$ & No $\mathrm{FE}^{\dagger}$ & Prov pairs \\
\hline & & Trad. FE & & Cond. FE \\
\hline & (I) & (II) & (III) & (IV) \\
\hline \multirow[t]{2}{*}{$\operatorname{Ln}\left(\mathrm{Pop}_{\mathrm{i}}\right)(\mathrm{B})$} & $0.847^{* * *}$ & $0.832^{* * *}$ & $0.909^{* * *}$ & $0.842^{* * *}$ \\
\hline & $(0.0463)$ & $(0.0484)$ & $(0.0258)$ & $(0.0115)$ \\
\hline \multirow[t]{2}{*}{$\operatorname{Ln}\left(\mathrm{Pop}_{\mathrm{j}}\right)(\mathrm{B})$} & $0.740^{* * *}$ & $0.699^{* * *}$ & $0.860^{* * *}$ & $0.701^{* * *}$ \\
\hline & $(0.0485)$ & $(0.0528)$ & $(0.0289)$ & $(0.0118)$ \\
\hline \multirow[t]{2}{*}{$\operatorname{Ln}\left(\right.$ Dist $\left._{i j}\right)$} & $-0.318^{* * *}$ & $-0.427^{* * *}$ & $-0.184^{* * *}$ & $-0.225^{* * *}$ \\
\hline & $(0.0984)$ & $(0.123)$ & $(0.0634)$ & $(0.0281)$ \\
\hline \multirow[t]{2}{*}{$2001 * \operatorname{Ln}\left(\right.$ Dist $\left._{\mathrm{ij}}\right)$} & 0.0256 & 0.0264 & $0.0641^{* * *}$ & $0.0316^{* * *}$ \\
\hline & $(0.0193)$ & $(0.0190)$ & $(0.0217)$ & $(0.0107)$ \\
\hline \multirow[t]{2}{*}{$2006^{*} \operatorname{Ln}\left(\right.$ Dist $\left._{\mathrm{ij}}\right)$} & 0.0133 & 0.0125 & $0.109^{* * *}$ & $0.0435^{* * *}$ \\
\hline & $(0.0200)$ & (0.0197) & (0.0235) & $(0.0109)$ \\
\hline \multirow[t]{2}{*}{ HomeProv $_{i j}$} & $1.005^{* * *}$ & $0.977^{* * *}$ & $1.258^{* * *}$ & $0.100^{*}$ \\
\hline & $(0.0838)$ & $(0.0814)$ & $(0.0520)$ & $(0.0584)$ \\
\hline \multirow[t]{2}{*}{ DiffEmRateGap $_{\mathrm{ij}}$} & $0.0260^{* * *}$ & $0.0245^{* * *}$ & $0.0249^{* * *}$ & $0.0235^{* * *}$ \\
\hline & $(0.00583)$ & $(0.00587)$ & $(0.00462)$ & $(0.00309)$ \\
\hline \multirow[t]{2}{*}{ DiffLnMedHIdlnc $c_{i j}(B)$} & $0.754^{* * *}$ & $0.645^{* *}$ & $0.691^{* * *^{\prime}}$ & $0.641^{* * *^{\prime}}$ \\
\hline & $(0.260)$ & $(0.275)$ & $(0.134)$ & $(0.0570)$ \\
\hline \multirow[t]{2}{*}{ AbsDiffFrePop $_{\mathrm{ij}}(\mathrm{B})$} & $-0.0149^{* * *}$ & $-0.0152^{* * *}$ & $-0.0193^{* * *}$ & $-0.0165^{* * *}$ \\
\hline & $(0.00125)$ & $(0.00127)$ & $(0.000726)$ & $(0.000437)$ \\
\hline \multirow[t]{2}{*}{$\mathrm{MR}_{\mathrm{ij}}$} & -0.152 & -0.0591 & $-0.534^{* * *}$ & $-0.231^{* * *}$ \\
\hline & (0.105) & $(0.124)$ & $(0.0577)$ & $(0.0242)$ \\
\hline \multirow{2}{*}{ Adjacent $_{i j}$} & $0.360^{* * *}$ & $0.347^{* * *}$ & $0.821^{* * *}$ & $0.294^{* * *}$ \\
\hline & $(0.0792)$ & $(0.0792)$ & $(0.0833)$ & $(0.0267)$ \\
\hline \multirow[t]{2}{*}{ RateHomeOwn $n_{i}(B)$} & $-0.0220^{* * *}$ & $-0.0267^{* * *}$ & $-0.0205^{* * *}$ & $-0.0240^{* * *}$ \\
\hline & $(0.00671)$ & $(0.00703)$ & $(0.00413)$ & $(0.00181)$ \\
\hline \multirow[t]{2}{*}{ AvgHomeVal ${ }_{j}(B)$} & -0.0117 & -0.0130 & $0.0430^{* * *}$ & $-0.0137^{* * *}$ \\
\hline & $(0.0123)$ & $(0.0125)$ & $(0.00711)$ & (0.00279) \\
\hline \multirow[t]{2}{*}{ DiffLowTax $_{i j}$} & $0.0527^{* * *}$ & $0.0507^{* * *}$ & 0.0187 & $0.0247^{* * *}$ \\
\hline & $(0.0128)$ & $(0.00880)$ & $(0.0117)$ & $(0.00718)$ \\
\hline \multirow[t]{2}{*}{ DiffMidTax $_{i j}$} & 0.0131 & $0.0211^{*}$ & $0.0404^{* * *}$ & $0.0221^{* *}$ \\
\hline & $(0.0148)$ & $(0.0127)$ & $(0.0141)$ & $(0.00967)$ \\
\hline \multirow[t]{2}{*}{ DiffHiTax $_{i j}$} & $-0.0758^{* * *}$ & $-0.0770^{* * *}$ & $-0.0750^{* * *}$ & $-0.0413^{* * *}$ \\
\hline & $(0.0107)$ & $(0.0109)$ & $(0.00966)$ & $(0.00642)$ \\
\hline \multirow[t]{2}{*}{ Pct15to29i $(B)$} & $0.0368^{*}$ & 0.0105 & $0.111^{* * *}$ & $0.0356^{* * *}$ \\
\hline & $(0.0210)$ & $(0.0224)$ & $(0.0116)$ & $(0.00595)$ \\
\hline DiffOtherlnc $_{\mathrm{ij}}(\mathrm{B})$ & $0.0270^{*}$ & $0.0332^{* *}$ & 0.00481 & $0.0194^{* * *}$ \\
\hline & $(0.0140)$ & $(0.0152)$ & (0.00599) & $(0.00290)$ \\
\hline $\mathrm{AboPop}_{\mathrm{i}}(\mathrm{B})$ & 0.00296 & 0.00564 & 0.00123 & $0.00523^{* * *}$ \\
\hline & $(0.00418)$ & $(0.00414)$ & $(0.00163)$ & $(0.000788)$ \\
\hline $\mathrm{AboPop}_{\mathrm{j}}(\mathrm{B})$ & $-0.0140^{* * *}$ & $-0.0137^{* *}$ & $-0.0198^{* * *}$ & $-0.0191^{* * *}$ \\
\hline & $(0.00510)$ & $(0.00534)$ & (0.00259) & $(0.00115)$ \\
\hline DiffJanTemp $_{\mathrm{ij}}$ & 0.00532 & 0.00417 & 0.00404 & $0.00623^{* * *}$ \\
\hline & $(0.00970)$ & $(0.0105)$ & $(0.00522)$ & $(0.00224)$ \\
\hline DiffRain $_{\mathrm{ij}}$ & -0.000651 & -0.000731 & -0.00176 & $-0.000884^{* *}$ \\
\hline & $(0.00245)$ & (0.00249) & (0.00107) & $(0.000450)$ \\
\hline $\mathrm{AT}_{\mathrm{i}}$ & 0.145 & $0.452^{* *}$ & $-0.140^{*}$ & $0.642^{* * *}$ \\
\hline & $(0.144)$ & $(0.218)$ & $(0.0814)$ & $(0.0536)$ \\
\hline$Q C_{i}$ & -0.186 & -0.177 & $-0.496^{* * *}$ & $-0.150^{* *}$ \\
\hline & $(0.190)$ & $(0.188)$ & $(0.0985)$ & $(0.0680)$ \\
\hline $\mathrm{PR}_{\mathrm{i}}$ & $0.367^{* * *}$ & $0.510^{* * *}$ & -0.0162 & $0.541^{* * *}$ \\
\hline & $(0.132)$ & $(0.165)$ & $(0.0691)$ & $(0.0483)$ \\
\hline $\mathrm{BC}_{\mathrm{i}}$ & 0.0699 & 0.162 & -0.0227 & $0.342^{* * *}$ \\
\hline & $(0.190)$ & $(0.204)$ & $(0.0967)$ & $(0.0601)$ \\
\hline
\end{tabular}




\begin{tabular}{lcccc}
$\mathrm{AT}_{\mathrm{j}}$ & $0.647^{* * *}$ & $0.732^{* * *}$ & $0.584^{* * *}$ & $1.004^{* * *}$ \\
$\mathrm{QC} \mathrm{C}_{\mathrm{j}}$ & $(0.139)$ & $(0.229)$ & $(0.0840)$ & $(0.0539)$ \\
& $0.350^{* *}$ & $0.305^{*}$ & $0.588^{* * *}$ & $0.498^{* * *}$ \\
$\mathrm{PR}_{\mathrm{j}}$ & $(0.175)$ & $(0.184)$ & $(0.0977)$ & $(0.0670)$ \\
& $0.503^{* * *}$ & $0.648^{* * *}$ & $0.406^{* * *}$ & $0.822^{* * *}$ \\
$\mathrm{BC}$ & $(0.137)$ & $(0.157)$ & $(0.0743)$ & $(0.0463)$ \\
& $0.740^{* * *}$ & $0.851^{* * *}$ & $0.393^{* * *}$ & $0.555^{* * *}$ \\
2001 & $(0.177)$ & $(0.192)$ & $(0.0927)$ & $(0.0570)$ \\
& -0.138 & -0.198 & $-0.340^{* *}$ & $-0.147^{*}$ \\
2006 & $(0.142)$ & $(0.144)$ & $(0.155)$ & $(0.0763)$ \\
& -0.0788 & -0.138 & $-0.573^{* * *}$ & $-0.195^{* *}$ \\
Constant & $(0.149)$ & $(0.151)$ & $(0.167)$ & $(0.0772)$ \\
& $-11.55^{* * *}$ & $-9.243^{* * *}$ & $-16.92^{* * *}$ & $-16.93^{* * *}$ \\
\hline Over-dispersion test (Ln(alpha)) & $(1.333)$ & $(1.645)$ & $(0.903)$ & $(0.412)$ \\
& - & - & 0.455 & - \\
\hline Border effect & & & $(0.0255)$ & \\
\hline N. of cases & $\mathbf{2 . 7 3}$ & $\mathbf{2 . 6 6}$ & $\mathbf{3 . 5 2}$ & 1.11 \\
Log pseudo-likelihood & 14,076 & 14,076 & 14,076 & 14,076 \\
Likelihood ratio & $-1,140,874$ & $-1,390,242$ & $-73,339$ & $-69,310$ \\
AlC & 6,647 & 7,555 & 12,380 & 41,482 \\
BIC & $2,821,813$ & $2,780,571$ & 146,745 & 138,686 \\
\hline
\end{tabular}

(B) denotes variable measured at beginning-of-period. Standard errors in parentheses.

Cluster-robust standard errors at the economic region pair level.

Source: Statistics Canada Census 1991, 1996, 2001 and 2006

${ }^{*} p<0.10,{ }^{* *} p<0.05,{ }^{* * *} p<0.01$ 
Chart 1: Percentage of Recent Migrants (5 Years Prior) in ER's Population, by Migration Source, Ranked Highest to Lowest, 2006 Census

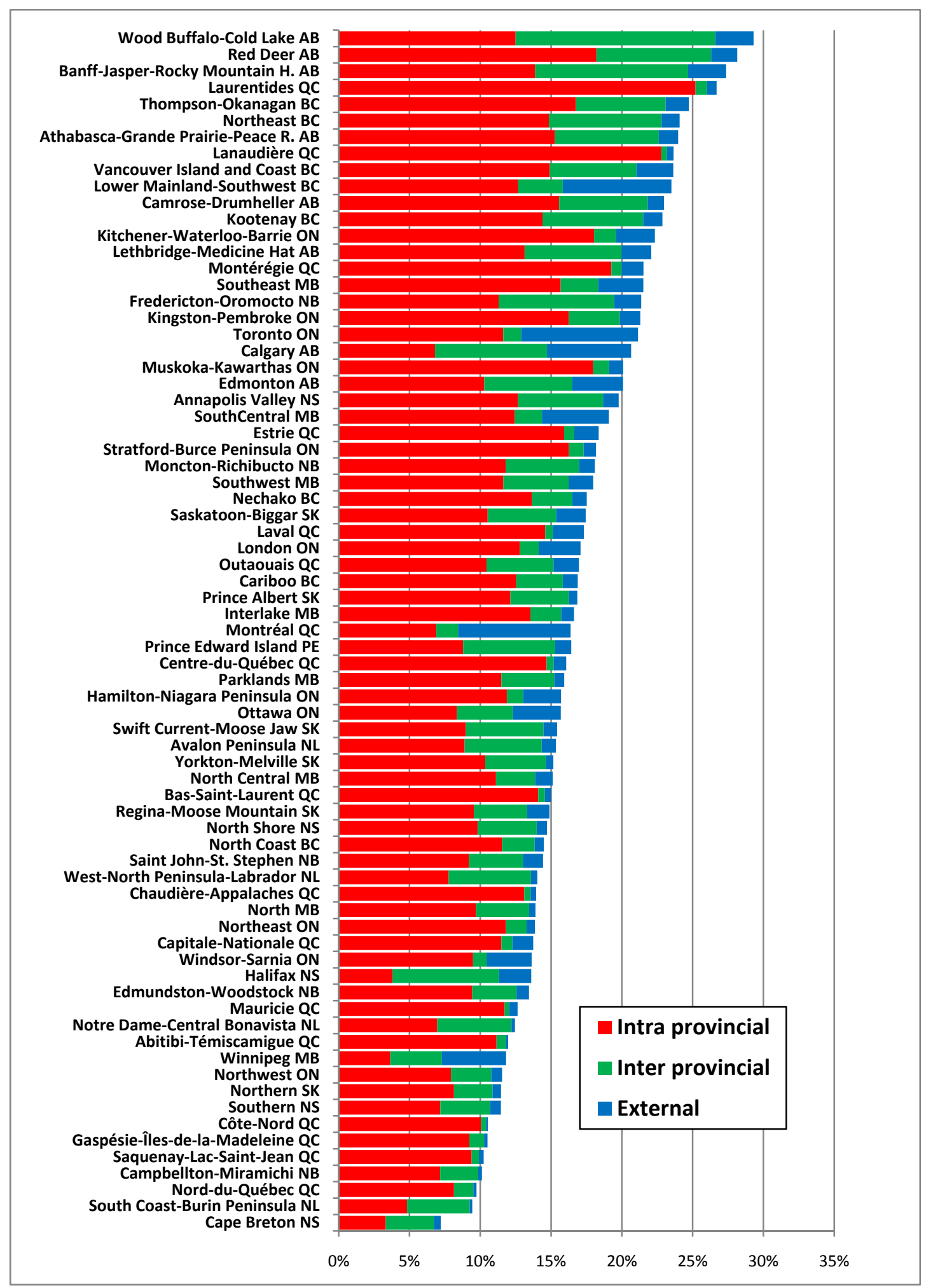


Chart 2: Distribution of Gross Migration Flows (up to 1000 migrants)

Census 1991-2006

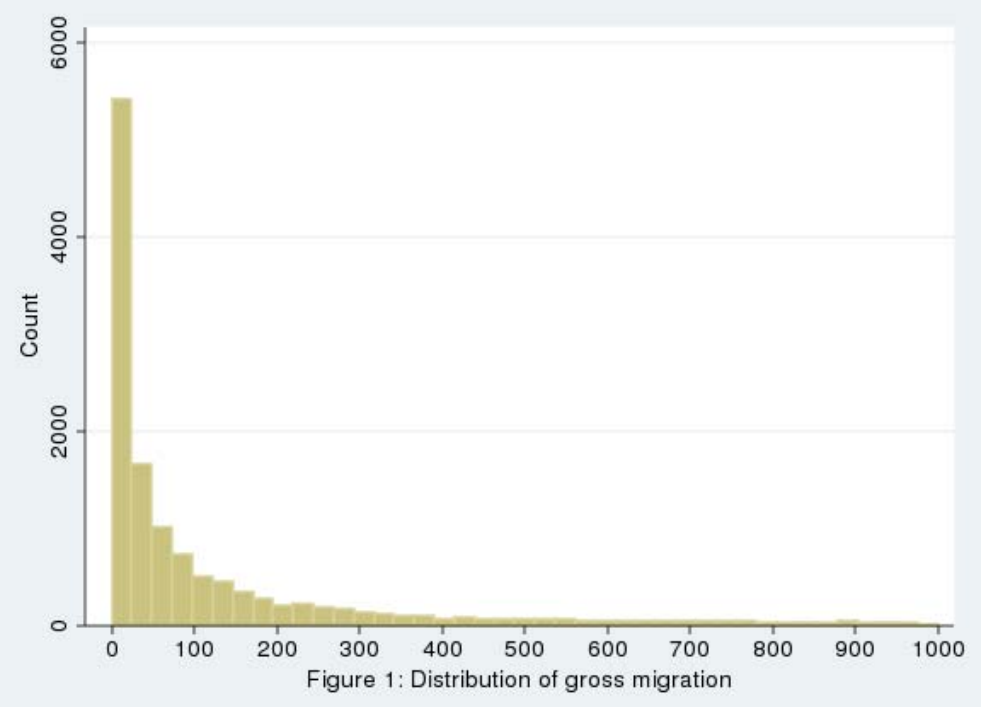




\section{Appendix A}

Economic Regions By Province

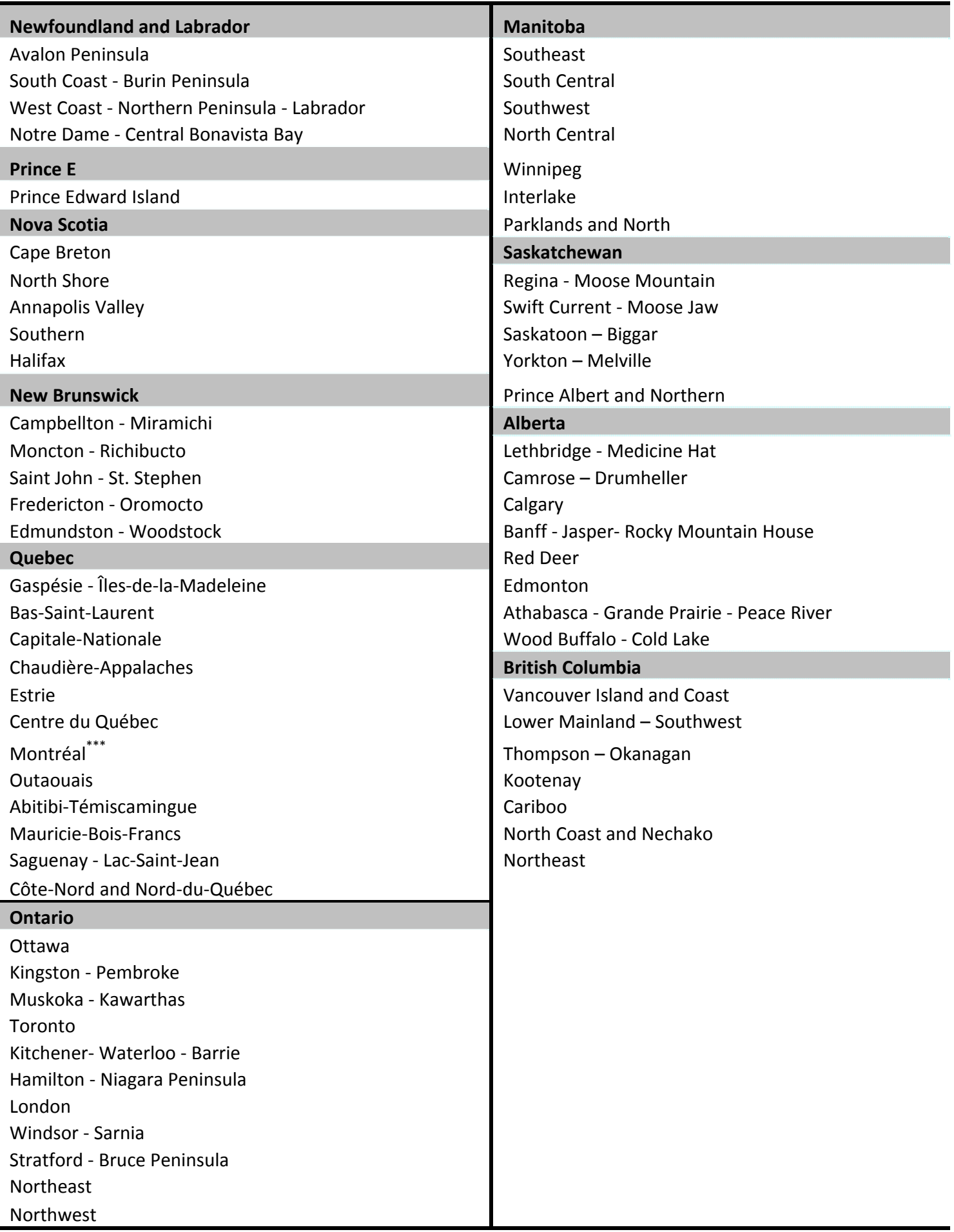

*** In our analysis, the ER of Montréal also includes the ERs of Lanaudière, Laurentides, Laval and Montérégie Source: Statistics Canada 


\section{Appendix B}

Poisson and Negative Binomial Results (dep var: gross flows)

\begin{tabular}{|c|c|c|c|c|c|}
\hline & \multicolumn{2}{|c|}{ Poisson } & \multicolumn{3}{|c|}{ Negative Binomial } \\
\hline & $\begin{array}{l}\text { Prov Pairs } \\
\text { Trad. } \mathrm{FE}^{+}\end{array}$ & $\begin{array}{l}\text { ER Pairs } \\
\text { Trad. FE }\end{array}$ & $\begin{array}{l}\text { O\&D Provs } \\
\text { Trad. } \mathrm{FE}^{++}\end{array}$ & $\begin{array}{l}\text { Prov Pairs } \\
\text { Trad. } \mathrm{FE}^{++}\end{array}$ & $\begin{array}{l}\text { ER pairs } \\
\text { Cond. FE }\end{array}$ \\
\hline & (I) & (II) & (III) & (IV) & $(\mathrm{V})$ \\
\hline \multirow[t]{2}{*}{$\operatorname{Ln}\left(\mathrm{Pop}_{\mathrm{i}}\right)(\mathrm{B})$} & $0.850^{* * *}$ & -0.0380 & $0.949^{* * *}$ & $0.954^{* * *}$ & $0.859^{* * *}$ \\
\hline & $(0.0585)$ & $(0.293)$ & $(0.0251)$ & $(0.0237)$ & $(0.0239)$ \\
\hline \multirow[t]{2}{*}{$\operatorname{Ln}\left(\mathrm{Pop}_{\mathrm{j}}\right)(\mathrm{B})$} & $0.718^{* * *}$ & -0.684 & $0.803^{* * *}$ & $0.804^{* * *}$ & $0.825^{* * *}$ \\
\hline & $(0.0663)$ & $(0.543)$ & $(0.0294)$ & $(0.0271)$ & $(0.0252)$ \\
\hline \multirow[t]{2}{*}{$\operatorname{Ln}\left(\right.$ Dist $\left._{i j}\right)$} & -0.217 & - & $-0.415^{* * *}$ & $-0.343^{* * *}$ & $-0.321^{* * *}$ \\
\hline & $(0.172)$ & - & $(0.0637)$ & $(0.0678)$ & $(0.0564)$ \\
\hline \multirow[t]{2}{*}{$2001 * \operatorname{Ln}\left(\right.$ Dist $\left._{i j}\right)$} & 0.0278 & 0.0186 & $0.0571^{* * *}$ & $0.0470^{* *}$ & $0.0229^{* * *}$ \\
\hline & $(0.0291)$ & $(0.0121)$ & $(0.0213)$ & $(0.0208)$ & $(0.00581)$ \\
\hline \multirow{2}{*}{$2006^{*} \operatorname{Ln}\left(\right.$ Dist $\left._{\mathrm{ij}}\right)$} & 0.00967 & 0.00602 & $0.0953^{* * *}$ & $0.0757^{* * *}$ & $0.0196^{* * *}$ \\
\hline & $(0.0348)$ & $(0.0110)$ & $(0.0222)$ & $(0.0217)$ & $(0.00593)$ \\
\hline \multirow[t]{2}{*}{ HomeProv $_{i j}$} & - & - & $1.209^{* * *}$ & $0.924^{* * *}$ & $0.890^{* * *}$ \\
\hline & - & - & $(0.0566)$ & $(0.0723)$ & $(0.0780)$ \\
\hline \multirow[t]{2}{*}{ DiffEmRateGap $_{\mathrm{ij}}$} & $0.0241^{* * *}$ & $0.0210^{* * *}$ & $0.0258^{* * *}$ & $0.0262^{* * *}$ & $0.0207^{* * *}$ \\
\hline & $(0.00596)$ & $(0.00303)$ & $(0.00470)$ & $(0.00475)$ & $(0.00218)$ \\
\hline \multirow[t]{2}{*}{ DiffLnMedHIdInc $c_{i j}(B)$} & $0.636^{* * *}$ & $0.929^{* *}$ & $0.434^{* * *}$ & $0.472^{* * *}$ & $0.531^{* * *}$ \\
\hline & $(0.163)$ & $(0.366)$ & $(0.128)$ & $(0.122)$ & $(0.0974)$ \\
\hline \multirow[t]{2}{*}{ AbsDiffFrePop $_{\mathrm{ij}}(\mathrm{B})$} & $-0.0149^{* * *}$ & -0.00305 & $-0.0198^{* * *}$ & $-0.0162^{* * *}$ & $-0.0161^{* * *}$ \\
\hline & $(0.00426)$ & $(0.00354)$ & $(0.000705)$ & $(0.00136)$ & $(0.000720)$ \\
\hline \multirow[t]{2}{*}{$\mathrm{MR}_{\mathrm{ij}}$} & -0.110 & 0.406 & $-0.360^{* * *}$ & $-0.365^{* * *}$ & $-0.480^{* * *}$ \\
\hline & (0.199) & $(0.667)$ & $(0.0597)$ & $(0.0591)$ & $(0.0543)$ \\
\hline \multirow[t]{2}{*}{ Adjacent $_{\mathrm{ij}}$} & $0.507^{* * *}$ & - & $0.773^{* * *}$ & $0.753^{* * *}$ & $-0.604^{* * *}$ \\
\hline & $(0.135)$ & - & $(0.0847)$ & $(0.0802)$ & $(0.0913)$ \\
\hline \multirow[t]{2}{*}{ RateHomeOwn $n_{i}(B)$} & $-0.0293^{* * *}$ & $0.0395^{* *}$ & $-0.0298^{* * *}$ & $-0.0304^{* * *}$ & $-0.0130^{* * *}$ \\
\hline & $(0.0106)$ & $(0.0172)$ & $(0.00411)$ & $(0.00404)$ & $(0.00239)$ \\
\hline \multirow[t]{2}{*}{ AvgHomeVal $(\mathrm{B})$} & -0.0104 & $-0.0257^{* * *}$ & 0.00967 & 0.00725 & $-0.0335^{* * *}$ \\
\hline & $(0.0153)$ & $(0.00606)$ & (0.00695) & $(0.00645)$ & $(0.00317)$ \\
\hline \multirow[t]{2}{*}{ DiffLowTax $_{i j}$} & $0.0343^{* *}$ & $0.0658^{* * *}$ & $0.0193^{*}$ & $0.0189^{*}$ & $0.0424^{* * *}$ \\
\hline & $(0.0147)$ & $(0.00815)$ & $(0.0115)$ & $(0.0111)$ & (0.00559) \\
\hline \multirow[t]{2}{*}{ DiffMidTax $_{i j}$} & 0.0270 & -0.00494 & $0.0404^{* * *}$ & $0.0391^{* * *}$ & 0.00383 \\
\hline & $(0.0175)$ & $(0.00902)$ & $(0.0136)$ & $(0.0135)$ & $(0.00736)$ \\
\hline \multirow[t]{2}{*}{ DiffHiTax $_{i j}$} & $-0.0702^{* * *}$ & $-0.0595^{* * *}$ & $-0.0582^{* * *}$ & $-0.0565^{* * *}$ & $-0.0498^{* * *}$ \\
\hline & $(0.0151)$ & $(0.00753)$ & (0.00992) & $(0.00980)$ & $(0.00467)$ \\
\hline \multirow[t]{2}{*}{ Pct15to29 $_{i}$ (B) } & 0.00112 & 0.0107 & $0.0305^{* * *}$ & $0.0332^{* * *}$ & $0.0225^{* * *}$ \\
\hline & $(0.0304)$ & $(0.0192)$ & $(0.0116)$ & $(0.0112)$ & $(0.00636)$ \\
\hline \multirow[t]{2}{*}{ DiffOtherlnc $_{\mathrm{ij}}(\mathrm{B})$} & $0.0357^{* *}$ & $0.0493^{* * *}$ & $0.0186^{* * *}$ & $0.0170^{* * *}$ & $0.0284^{* * *}$ \\
\hline & $(0.0175)$ & $(0.0172)$ & $(0.00625)$ & $(0.00586)$ & $(0.00359)$ \\
\hline AboPop $_{i}(B)$ & 0.00448 & 0.00348 & $0.00613^{* * *}$ & $0.00578^{* * *}$ & $0.00524^{* * *}$ \\
\hline & $(0.00372)$ & $(0.0133)$ & $(0.00171)$ & $(0.00155)$ & $(0.00162)$ \\
\hline AboPop $_{j}(B)$ & $-0.0153^{* *}$ & 0.00171 & $-0.0149^{* * *}$ & $-0.0171^{* * *}$ & $-0.0155^{* * *}$ \\
\hline & (0.00598) & $(0.00553)$ & $(0.00260)$ & $(0.00242)$ & $(0.00205)$ \\
\hline DiffJanTemp $_{\mathrm{ij}}$ & 0.00325 & - & 0.00286 & 0.00507 & $0.0117^{* *}$ \\
\hline & $(0.00666)$ & - & $(0.00613)$ & $(0.00538)$ & $(0.00496)$ \\
\hline DiffRain $_{\mathrm{ij}}$ & -0.000909 & - & -0.00103 & -0.00159 & $-0.00199^{*}$ \\
\hline & $(0.00162)$ & - & (0.00117) & (0.000999) & (0.00105) \\
\hline $\mathrm{AT}_{\mathrm{i}}$ & - & - & $0.414^{* * *}$ & $0.868^{* * *}$ & -0.0298 \\
\hline & - & - & $(0.141)$ & $(0.327)$ & $(0.0874)$ \\
\hline$Q C_{i}$ & - & - & $-0.331^{* * *}$ & $-0.682^{* * *}$ & $-0.959^{* * *}$ \\
\hline & - & - & $(0.101)$ & $(0.204)$ & $(0.0879)$ \\
\hline $\mathrm{PR}_{\mathrm{i}}$ & - & - & $0.510^{* * *}$ & 0.151 & 0.0419 \\
\hline & - & - & (0.0938) & $(0.138)$ & $(0.0803)$ \\
\hline
\end{tabular}




\begin{tabular}{lccccc}
$\mathrm{BC}_{\mathrm{i}}$ & - & - & 0.139 & $0.358^{* *}$ & -0.0702 \\
& - & - & $(0.0974)$ & $(0.147)$ & $(0.0970)$ \\
$\mathrm{AT}_{\mathrm{j}}$ & - & - & $0.352^{* * *}$ & 0.222 & 0.0678 \\
& - & - & $(0.133)$ & $(0.148)$ & $(0.0848)$ \\
$\mathrm{QC}_{\mathrm{j}}$ & - & - & $0.278^{* * *}$ & 0.162 & $-0.369^{* * *}$ \\
& - & - & $(0.0975)$ & $(0.194)$ & $(0.0818)$ \\
$\mathrm{PR}_{\mathrm{j}}$ & - & - & $0.955^{* * *}$ & $0.812^{* * *}$ & 0.0433 \\
& - & - & $(0.0928)$ & $(0.143)$ & $(0.0793)$ \\
$\mathrm{BC}_{\mathrm{j}}$ & - & - & $0.638^{* * *}$ & $0.980^{* * *}$ & $0.197^{* *}$ \\
& - & - & $(0.0943)$ & $(0.152)$ & $(0.0956)$ \\
2001 & -0.225 & -0.0830 & $-0.440^{* * *}$ & $-0.354^{* *}$ & $-0.114^{* * *}$ \\
& $(0.173)$ & $(0.129)$ & $(0.151)$ & $(0.147)$ & $(0.0393)$ \\
2006 & -0.142 & -0.0940 & $-0.689^{* * *}$ & $-0.524^{* * *}$ & $-0.0821^{*}$ \\
& $(0.193)$ & $(0.148)$ & $(0.158)$ & $(0.153)$ & $(0.0421)$ \\
Constant & - & - & $-12.45^{* * *}$ & $-13.24^{* * *}$ & $-16.15^{* * *}$ \\
& - & - & $(0.931)$ & $(0.934)$ & $(0.733)$ \\
\hline Over-dispersion test (Ln(alpha)) & - & - & $0.407^{* * *}$ & $0.343^{* * *}$ & - \\
& & & $(0.0250)$ & $(0.0254)$ & \\
\hline Border effect & - & - & 3.25 & 2.52 & $\mathbf{2 . 4 4}$ \\
\hline $\mathrm{N}$. of cases & 14076 & 12606 & 14,076 & 14,076 & 12,606 \\
Log pseudo-likelihood & $-1,166,443$ & $-186,142$ & $-73,050$ & $-72,686$ & $-38,838$ \\
Likelihood ratio & 40,917 & 1,400 & 12,262 & 19,814 & 12,880 \\
AlC & $2,332,932$ & 372,323 & 146,187 & 145,618 & 77,742 \\
$\mathrm{BIC}$ & $2,333,106$ & 372,464 & 146,520 & 146,547 & 77,988 \\
\hline
\end{tabular}

(B) denotes variables measured at beginning-of-period. Standard errors in parentheses.

${ }^{+}$Cluster-robust standard errors at the province-pair level.

${ }^{+\dagger}$ Cluster-robust standard errors at the economic region pair level.

Source: Statistics Canada Census 1991, 1996, 2001 and 2006

${ }^{*} p<0.10,{ }^{* *} p<0.05,{ }^{* * *} p<0.01$ 


\section{Appendix C}

Poisson and Negative Binomial Results (dep var: gross flows/100)

\begin{tabular}{|c|c|c|c|c|}
\hline & \multicolumn{2}{|c|}{ Poisson } & \multicolumn{2}{|c|}{ Negative Binomial } \\
\hline & No $\mathrm{FE}^{+}$ & O\&D Provs $^{\dagger}$ & No $\mathrm{FE}^{\dagger}$ & Prov pairs \\
\hline & & Trad. FE & & Cond. FE \\
\hline & (I) & (II) & (III) & (IV) \\
\hline \multirow[t]{2}{*}{$\operatorname{Ln}\left(\operatorname{Pop}_{\mathrm{i}}\right)(\mathrm{B})$} & $0.847^{* * *}$ & $0.832^{* * *}$ & $0.911^{* * *}$ & $0.880^{* * *}$ \\
\hline & $(0.0463)$ & (0.0484) & $(0.0225)$ & $(0.0121)$ \\
\hline \multirow[t]{2}{*}{$\operatorname{Ln}\left(\operatorname{Pop}_{\mathrm{j}}\right)(\mathrm{B})$} & $0.740^{* * *}$ & $0.699^{* * *}$ & $0.851^{* * *}$ & $0.765^{* * *}$ \\
\hline & (0.0485) & (0.0528) & $(0.0268)$ & (0.0133) \\
\hline \multirow[t]{2}{*}{$\operatorname{Ln}\left(\right.$ Dist $\left._{\mathrm{ij}}\right)$} & $-0.318^{* * *}$ & $-0.427^{* * *}$ & $-0.188^{* * *}$ & $-0.138^{* * *}$ \\
\hline & $(0.0984)$ & $(0.123)$ & $(0.0564)$ & $(0.0359)$ \\
\hline \multirow[t]{2}{*}{$2001 * \operatorname{Ln}\left(\right.$ Dist $\left._{\mathrm{ij}}\right)$} & 0.0256 & 0.0264 & $0.0386^{*}$ & 0.0153 \\
\hline & (0.0193) & (0.0190) & $(0.0222)$ & (0.0113) \\
\hline \multirow[t]{2}{*}{$2006 * \operatorname{Ln}\left(\right.$ Dist $\left._{i j}\right)$} & 0.0133 & 0.0125 & $0.0586^{* * *}$ & 0.0170 \\
\hline & $(0.0200)$ & (0.0197) & $(0.0227)$ & $(0.0114)$ \\
\hline \multirow[t]{2}{*}{ HomeProv $_{\mathrm{ij}}$} & $1.005^{* * *}$ & $0.977^{* * *}$ & $1.092^{* * *}$ & $-1.244^{* * *}$ \\
\hline & $(0.0838)$ & $(0.0814)$ & $(0.0494)$ & $(0.142)$ \\
\hline \multirow{2}{*}{ DiffEmRateGap $_{\mathrm{ij}}$} & $0.0260^{* * *}$ & $0.0245^{* * *}$ & $0.0253^{* * *}$ & $0.0252^{* * *}$ \\
\hline & $(0.00583)$ & $(0.00587)$ & (0.00319) & $(0.00342)$ \\
\hline \multirow[t]{2}{*}{ DiffLnMedHIdlnc $c_{i j}(B)$} & $0.754^{* * *}$ & $0.645^{* *}$ & $0.779^{* * *}$ & $0.808^{* * *}$ \\
\hline & $(0.260)$ & $(0.275)$ & $(0.124)$ & $(0.0645)$ \\
\hline \multirow[t]{2}{*}{ AbsDiffFrePop $_{\mathrm{ij}}(\mathrm{B})$} & $-0.0149^{* * *}$ & $-0.0152^{* * *}$ & $-0.0175^{* * *}$ & $-0.0149^{* * *}$ \\
\hline & $(0.00125)$ & $(0.00127)$ & (0.000659) & $(0.000635)$ \\
\hline \multirow[t]{2}{*}{$M R_{i j}$} & -0.152 & -0.0591 & $-0.474^{* * *}$ & $-0.291^{* * *}$ \\
\hline & $(0.105)$ & $(0.124)$ & $(0.0493)$ & $(0.0277)$ \\
\hline \multirow[t]{2}{*}{ Adjacent $_{\mathrm{ij}}$} & $0.360^{* * *}$ & $0.347^{* * *}$ & $0.568^{* * *}$ & $0.394^{* * *}$ \\
\hline & $(0.0792)$ & $(0.0792)$ & $(0.0625)$ & $(0.0290)$ \\
\hline \multirow[t]{2}{*}{ RateHomeOwn $n_{i}(B)$} & $-0.0220^{* * *}$ & $-0.0267^{* * *}$ & $-0.0226^{* * *}$ & $-0.0293^{* * *}$ \\
\hline & $(0.00671)$ & $(0.00703)$ & $(0.00394)$ & (0.00199) \\
\hline \multirow[t]{2}{*}{ AvgHomeVal ${ }_{j}(B)$} & -0.0117 & -0.0130 & $0.0137^{* *}$ & -0.00409 \\
\hline & $(0.0123)$ & $(0.0125)$ & $(0.00631)$ & $(0.00299)$ \\
\hline \multirow[t]{2}{*}{ DiffLowTax $_{i j}$} & $0.0527^{* * *}$ & $0.0507^{* * *}$ & $0.0395^{* * *}$ & $0.0319^{* * *}$ \\
\hline & $(0.0128)$ & $(0.00880)$ & $(0.00744)$ & (0.00830) \\
\hline \multirow[t]{2}{*}{ DiffMidTax $_{i j}$} & 0.0131 & $0.0211^{*}$ & $0.0150^{*}$ & $0.0232^{* *}$ \\
\hline & $(0.0148)$ & $(0.0127)$ & $(0.00897)$ & $(0.0116)$ \\
\hline \multirow[t]{2}{*}{ DiffHiTax $_{i j}$} & $-0.0758^{* * *}$ & $-0.0770^{* * *}$ & $-0.0674^{* * *}$ & $-0.0564^{* * *}$ \\
\hline & $(0.0107)$ & $(0.0109)$ & $(0.00612)$ & (0.00755) \\
\hline \multirow[t]{2}{*}{ Pct15to29, $(B)$} & $0.0368^{*}$ & 0.0105 & $0.0581^{* * *}$ & $0.0278^{* * *}$ \\
\hline & $(0.0210)$ & $(0.0224)$ & $(0.0104)$ & (0.00657) \\
\hline \multirow[t]{2}{*}{ DiffOtherlnc $c_{i j}(B)$} & $0.0270^{*}$ & $0.0332^{* *}$ & $0.0174^{* * *}$ & $0.0250^{* * *}$ \\
\hline & $(0.0140)$ & $(0.0152)$ & $(0.00514)$ & $(0.00333)$ \\
\hline AboPop $_{i}(B)$ & 0.00296 & 0.00564 & $0.00515^{* * *}$ & $0.00755^{* * *}$ \\
\hline & $(0.00418)$ & $(0.00414)$ & $(0.00180)$ & $(0.00103)$ \\
\hline $\mathrm{AboPop}_{\mathrm{j}}(\mathrm{B})$ & $-0.0140^{* * *}$ & $-0.0137^{* *}$ & $-0.0146^{* * *}$ & $-0.0192^{* * *}$ \\
\hline & $(0.00510)$ & $(0.00534)$ & $(0.00266)$ & $(0.00129)$ \\
\hline DiffJanTemp $_{\mathrm{ij}}$ & 0.00532 & 0.00417 & 0.00644 & $0.00935^{* * *}$ \\
\hline & $(0.00970)$ & $(0.0105)$ & $(0.00455)$ & $(0.00251)$ \\
\hline DiffRain $_{i j}$ & -0.000651 & -0.000731 & $-0.00193^{*}$ & -0.000541 \\
\hline & $(0.00245)$ & (0.00249) & $(0.000987)$ & (0.000509) \\
\hline $\mathrm{AT}_{\mathrm{i}}$ & 0.145 & $0.452^{* *}$ & -0.0480 & $1.368^{* * *}$ \\
\hline & $(0.144)$ & $(0.218)$ & $(0.0777)$ & $(0.183)$ \\
\hline $\mathrm{QC}_{\mathrm{i}}$ & -0.186 & -0.177 & $-0.365^{* * *}$ & $-0.501^{* * *}$ \\
\hline & $(0.190)$ & $(0.188)$ & $(0.0877)$ & $(0.145)$ \\
\hline $\mathrm{PR}_{\mathrm{i}}$ & $0.367^{* * *}$ & $0.510^{* * *}$ & 0.0257 & $0.978^{* * *}$ \\
\hline & $(0.132)$ & $(0.165)$ & (0.0689) & $(0.136)$ \\
\hline
\end{tabular}




\begin{tabular}{lcccc}
$\mathrm{BC}_{\mathrm{i}}$ & 0.0699 & 0.162 & 0.0138 & $0.298^{* *}$ \\
& $(0.190)$ & $(0.204)$ & $(0.0873)$ & $(0.129)$ \\
$\mathrm{AT}_{\mathrm{j}}$ & $0.647^{* * *}$ & $0.732^{* * *}$ & $0.596^{* * *}$ & $3.450^{* * *}$ \\
& $(0.139)$ & $(0.229)$ & $(0.0773)$ & $(0.336)$ \\
$\mathrm{QC}_{\mathrm{j}}$ & $0.350^{* *}$ & $0.305^{* *}$ & $0.489^{* * *}$ & $1.742^{* * *}$ \\
& $(0.175)$ & $(0.184)$ & $(0.0820)$ & $(0.157)$ \\
$\mathrm{PR}_{\mathrm{j}}$ & $0.503^{* * *}$ & $0.648^{* * *}$ & $0.327^{* * *}$ & $1.817^{* * *}$ \\
& $(0.137)$ & $(0.157)$ & $(0.0683)$ & $(0.120)$ \\
$\mathrm{BC}_{\mathrm{j}}$ & $0.740^{* * *}$ & $0.851^{* * *}$ & $0.479^{* * *}$ & $0.477^{* * *}$ \\
& $(0.177)$ & $(0.192)$ & $(0.0812)$ & $(0.0968)$ \\
2001 & -0.138 & -0.198 & -0.209 & -0.0618 \\
& $(0.142)$ & $(0.144)$ & $(0.165)$ & $(0.0783)$ \\
2006 & -0.0788 & -0.138 & $-0.347^{* *}$ & -0.0763 \\
& $(0.149)$ & $(0.151)$ & $(0.170)$ & $(0.0790)$ \\
Constant & $-16.15^{* * *}$ & $-13.85^{* * *}$ & $-19.80^{* * *}$ & $-17.66^{* * *}$ \\
& $(1.333)$ & $(1.645)$ & $(0.745)$ & $(0.518)$ \\
\hline Over-dispersion test (Ln(alpha)) & - & - & $-1.484^{* * *}$ & - \\
& & & $(0.0598)$ & \\
\hline $\mathrm{N}$. of cases & 14,076 & 14,076 & 14,076 & 14,076 \\
Log pseudo-likelihood & $-25,929$ & $-25,723$ & $-18,856$ & $-19,178$ \\
Likelihood ratio & 6,647 & 7,555 & 12,429 & 35,048 \\
AlC & 51,924 & 51,531 & 37,781 & 38,422 \\
BIC & 52,173 & 51,856 & 38,038 & 38,671 \\
\hline
\end{tabular}

(B) denotes variable measured at beginning-of-period. Standard errors in parentheses.

${ }^{+}$Cluster-robust standard errors at the economic region pair level.

Source: Statistics Canada Census 1991, 1996, 2001 and 2006

${ }^{*} p<0.10,{ }^{* *} p<0.05,{ }^{* * *} p<0.01$ 